University of Windsor

Scholarship at UWindsor

Summer 2012

\title{
A game-theoretic analysis of social responsibility conduct in two- echelon supply chains
}

\author{
Debing Ni \\ Kevin W. Li Dr. \\ University of Windsor
}

Follow this and additional works at: https://scholar.uwindsor.ca/odettepub

Part of the Business Commons

\section{Recommended Citation}

$\mathrm{Ni}$, Debing and Li, Kevin W. Dr.. (2012). A game-theoretic analysis of social responsibility conduct in twoechelon supply chains. International Journal of Production Economics, 138 (2), 303-313.

https://scholar.uwindsor.ca/odettepub/56

This Article is brought to you for free and open access by the Odette School of Business at Scholarship at UWindsor. It has been accepted for inclusion in Odette School of Business Publications by an authorized administrator of Scholarship at UWindsor. For more information, please contact scholarship@uwindsor.ca. 


\section{A Game-Theoretic Analysis of Social Responsibility Conduct in Two-Echelon Supply}

\section{Chains}

Debing $\mathrm{Ni}^{1,2}$ and Kevin W. $\mathrm{Li}^{2,3^{*}}$

1 School of Management and Economics, University of Electronic Science and Technology of China, Chengdu, Sichuan, P. R. China, 610054

2 Odette School of Business, University of Windsor, Windsor, Ontario, Canada, N9B 3P4

3 Department of Value and Decision Science, Tokyo Institute of Technology, W9-38, 2-12-1 Ookayama, Meguro, Tokyo 152-8552, Japan

\section{Acknowledgments:}

Debing $\mathrm{Ni}$ would like to acknowledge the financial support from the Natural Sciences Foundation (NSF) of China (Grant \#: 70702025), the UESTC Funds for Junior Research Chairs as well as the Key Project of Natural Sciences Foundation (NSF) of China (Grant \#: 70932005). Kevin W. Li is grateful for the financial support from the Natural Sciences and Engineering Research Council of Canada (NSERC) under its Discovery Grant program. Kevin W. Li also wishes to express his gratitude to the Japan Society for the Promotion of Science (JSPS) for its Invitation Fellowship that allows him to complete the research reported in this article during his sabbatical leave between 20 June and 19 December 2011 in the Department of Value and Decision Science at the Tokyo Institute of Technology in Japan.

\footnotetext{
* Correspondence author, phone: 1-519-253-3000 ext 3456, fax: 1-519-973-7073, e-mail: kwli@uwindsor.ca
} 


\section{A Game-Theoretic Analysis of Social Responsibility Conduct in Two-Echelon Supply}

\section{Chains}

(1)

Abstract: This research investigates how two supply chain members, a downstream firm (F) and an upstream supplier (S), interact with each other with respect to corporate social responsibility (CSR) behaviour and what impact exogenous parameters may have on this interaction. A game-theoretic analysis is conducted to obtain equilibriums for both simultaneous-move and sequential-move CSR games. Under certain assumptions, it is concluded that (1) there exists a mutual incentive between their CSR behaviour, whereby a win-win performance in terms of both CSR and profitability is achieved as long as exogenous parameters exceed certain critical thresholds; (2) A higher consumer marginal social-benefit potential (MSBP) or a lower consumer marginal perception difficulty (MPD) helps to lower the critical thresholds of CSR budgets and CSR operational efficiency by S and F, making it easier to achieve the win-win performance; (3) An increase in one supply chain member's CSR budget or CSR operational efficiency tends to make the supply chain easier to attain a win-win performance scenario; (4) if CSR decisions are made sequentially, a prior commitment to CSR activities from one supply chain member strengthens the mutual incentive and facilitates the realization of the win-win performance. Business implications of these research findings are also discussed.

Keywords: Supply chain management; corporate social responsibility; game theory; mutual incentive; commitment

\section{Introduction}

With the continued trend of globalization, more and more firms have been taking advantage of global supply chains to improve their competitive edge by lowering cost, accelerating product development, and getting access to natural and human resources in the international arena (Boyd et al. 2004). As firms enjoy the benefits, many leading global brands such as Nike, GAP, Adidas, and McDonalds have been faced with intense pressure for socially responsible supply chain management (Amaeshi et al. 2008). A commonly observed response to this pressure is 
that the primary firm introduces codes of conduct to ensure its partners' business practices to be socially responsible (Pedersen and Andersen 2006). However, World Bank (2003) reports the difficulty in implementing these codes of conduct due to a wide variety of individual codes on corporate social responsibility (CSR), the effectiveness of the top-down CSR structure, and insufficient understanding of business benefits of CSR commitment.

CSR has historically been a significant theme in the business community and attracted considerable research interests from academia. For instance, a survey of the Economist (2005) shows that $85 \%$ of 136 executives and 65 investors view CSR as a "central” or "important" consideration in making investment decisions. Different lines of research have been conducted to examine CSR, including qualitative analysis (Bowen 1953, Friedman 1970), empirical investigations on the relationship between CSR and corporate financial performance (Orlitzky et al. 2003, Margolis and Walsh 2001, González-Benito and González-Benito 2005), and formal modeling of CSR (Baron 2001, 2007, Calveras et al. 2007, Giovanni and Giacinta 2007).

Currently, the majority of research on CSR focuses on individual firms. Recently, researchers have extended the view on CSR and investigated CSR from a supply chain management perspective. Research in this emerging field has taken on different avenues. For qualitative discussions, with the belief that the primary member of a supply chain is morally obligated to manage other members' CSR activities, Boyd et al. (2004) provide a nine-step procedure for supply chain CSR management. Amaeshi et al. (2008) suggest that the more powerful member in a supply chain bears a responsibility to influence the weaker member(s). Empirically, Carter et al. (2000) show that environmental purchasing has significant impact on both income and cost. Carter and Jennings (2002) find a positive relationship between CSR and supplier performance. And more recently, Miao et al. (2011) use a sample of Chinese firms to explore the antecedents of logistics social responsibility. Ageron et al. (2011) take advantage of a French sample to provide a list of enabling conditions and critical success factors for sustainable supply management. In addition, mathematical models have been established to investigate CSR in supply chains. For instance, Savaskan et al. (2004) identify an appropriate supply chain structure for original equipment manufacturers in closed-loop supply chains with product remanufacturing. Cruz (2008) develops a dynamic multi-criteria decision-making 
framework to derive the equilibriums for supply chain networks with environmental (social) responsibility, and the basic assumption is that environmental responsibility does not directly affect market demand. Cruz and Wakolbinger (2008) extend Cruz ( 2008 ) to a multi-period setting to capture the long-term effect of CSR activities. Hsueh and Chang (2008) demonstrate that system-wide optimization can be achieved by appropriately allocating social responsibility via monetary transfers among members in a supply chain network. Ni et al. (2010) examine social responsibility allocation in two-echelon supply chains, where the two supply chain members are bound by a wholesale price contract. A key issue is to determine who should be allocated as the responsibility holder with the right of offering the contract that is designed to characterize the transfer mechanism of social responsibility cost incurred by the supplier. Another concern in Ni et al. (2010) is to examine how this right should be appropriately restricted.

Taking a strategic CSR view (Baron 2001), this paper attempts to understand how two supply chain members, a downstream firm (F) and an upstream supplier (S), interact with each other with respect to CSR behaviour in a game-theoretic setting and what impact exogenous factors may have on this interaction and equilibriums. Compared to the otherwise identical product sold by competitors in the final market, the product provided by the supply chain differs with certain CSR commitment that is expected to bring consumers with additional benefits depending on consumers' perceptions. This assumption aims to address empirical findings about the effect of CSR performance on consumer's willingness-to-pay in Mohr and Webb (2005) and De Pelsmacker et al. (2005) and reflects the view that CSR performance can be viewed as a device for both vertical and horizontal product differentiation (McWilliams et al. 2006). The final market is assumed to be competitive via price, and this price competition results in a CSR-dependent demand function for the supply chain product due to the differentiation by CSR performance. With this demand function, a dynamic three-stage game model is established to characterize the strategic interaction between $\mathrm{S}$ and $\mathrm{F}$ in the two-echelon supply chain where the first stage is to capture the behavioural interaction regarding CSR conduct and the last two stages are a standard description of the good/service transaction in a supply chain with a wholesale contract. More specifically, Section 2 considers 
a simultaneous-move CSR game where S and F simultaneously determine their individual CSR commitment prior to F's purchase decision from S at a wholesale price set by S, F then sells the product or service in a final consumer market. Section 3 examines the situation that $\mathrm{S}$ and $\mathrm{F}$ declare their individual commitment to CSR activities sequentially (For example, in its 2006 annual CSR report, Starbucks announced (committed) the target percentage (66.9\%) of 2007 paper using that is made of post-consumer fiber), and this modified game is referred to as the sequential-move CSR game.

With the simultaneous-move CSR game, it is demonstrated that a mutual incentive exists between $\mathrm{F}$ and $\mathrm{S}$ and this mutual incentive leads to a win-win result in the sense that both the CSR and economic performance can be enhanced as long as exogenous parameters exceed certain thresholds (Proposition 2 and 3). Subsequently, it is explored how these thresholds are affected by each exogenous parameter (Proposition 4). An examination of the sequential-move CSR game reveals that the prior commitment to CSR activities by one member strengthens the mutual incentive and makes the win-win performance more likely to be realized by coordinating their social responsibility activities. The enhancement of the mutual incentive is reflected in the relaxation of the critical conditions for achieving the win-win performance (Proposition 5).

The research reported in this article falls within the category of mathematical modeling, but the models here significantly differ from the existing approaches. Savaskan et al. (2004) focus on the efficiency differences among four supply chain structures while we demonstrate how a win-win scenario can be achieved via the mutual incentive between $\mathrm{S}$ and $\mathrm{F}$, and this incentive may be further strengthened if a member is willing to declare its CSR commitment ahead of another member's CSR decision. In the multi-criteria decision-making framework, Cruz (2008) considers the cost associated with CSR activities and ignores the benefit of CSR commitment on market demand, but the research here accommodates both cost and benefit of CSR. More importantly, this article attempts to understand how to reach a win-win solution through strategic interaction between the two supply chain members while Cruz (2008) and Cruz and Wakolbinger (2008) explore the dynamic evolution of product flows, associated product prices, and different levels of social responsibility activities in supply chain networks. In Hsueh and Chang (2008), the proposed strategy for coordinating CSR in a supply chain 
network is accomplished by monetary transfers that are assumed to be exogenously binding, while the models here investigate how CSR activities endogenously interact. As for the difference from the research reported in Ni et al. (2010), this article assumes that each supply chain member incurs its individual CSR cost and the focus is to examine the strategic interaction between the two members. On the other hand, Ni et al. (2010) consider the situation that the cost associated with CSR only incurs by S and is expected to be shared with F through a wholesale price contract.

This research differs from the literature on the impact of quality and/or service on market demand in industrial organization (Tirole 1988) where quality/service reflects a vertical differentiation attribute of a product and a higher quality or service level always provides positive extra benefits to all consumers. On the other hand, the CSR performance here is modeled with both vertical and horizontal differentiation aspects where a product with CSR commitment may provide positive or negative extra benefits depending on consumers' perceptions. In addition, the research here focuses on the mutual incentive of CSR conduct between the upstream and downstream players, but the literature on quality improvement incentives under quality-related cost sharing contracts usually does not explicitly consider the impact of quality improvement on final demand or the downstream service competition/ coordination in the final market. More detailed comparisons are furnished in Section 2.2 when the basic model setting is explained.

The remainder of this article is organized as follows. Section 2 presents a simultaneousmove CSR game model with its equilibriums and comparative results. Section 3 considers the situation that the two members make their CSR decisions sequentially rather than simultaneously. A discussion about adopting quadratic CSR cost functions is furnished in Section 4 and the paper concludes with some remarks in Section 5.

\section{A Simultaneous-Move CSR Game}

\subsection{The Final Demand for CSR Products}

Consider a two-echelon supply chain with a downstream firm (F) and an upstream supplier (S). F purchases product/service from $\mathrm{S}$ at a wholesale price $w$ set by $\mathrm{S}$ and sells it in a final market where a large number of firms with a same constant marginal cost $\left(c_{0}=0\right)$ sell identical 
products via price competition. The products sold by $\mathrm{F}$ and other firms in the final market are only differentiated by CSR activities committed by F and S while other firms provide the same product without CSR commitment. The price competition implies that the equilibrium price of non-CSR goods $\left(p_{0}\right)$ is equal to their marginal cost (i.e. $\left.p_{0}=c_{0}=0\right){ }^{1}$

Assume that each consumer in the final market purchases at most 1 unit and has homogeneous preference on non-CSR goods provided by other firms, but consumers' preferences are heterogeneous on the CSR product provided by the supply chain. To characterize the difference in CSR preference, it is assumed that a consumer with type $\theta$ obtains an extra benefit $a y-b \theta$ (relative to 1 unit of non-CSR good) when he/she buys one unit of good with a given CSR activity ( $y$ ), where $a>0, b>0, \theta \geq 0 .^{2}$ Furthermore, if $y=0$, it is assumed that $a y-b \theta=0$ for all $\theta \geq 0$. This implies that the extra benefit will be zero if the supply chain system does not provide a differentiated product with CSR commitment.

This formulation of extra benefits intends to capture the following impact of CSR activities. Firstly, ay reflects a general intuition that each consumer could potentially benefit from CSR activity $y . a$ is hereafter called the marginal social-benefit potential (MSBP). For a given $y$, the greater the MSBP, the greater the potential social benefit is generated by this CSR activity. Secondly, $b \theta$ represents consumer $\theta$ 's difficulty to perceive the potential benefit of $y . b$ is referred to as the marginal perception difficulty (MPD). A higher MPD indicates that consumer $\theta$ feels more difficult to perceive the benefit. Finally, for given $a$, $y$ and $b$, different $\theta$ 's embody heterogeneous preferences for a given CSR activity: a consumer with a higher $\theta$ receives a lower level of extra benefit by consuming a unit of the CSR goods.

Moreover, in the above formulation of consumers' extra benefit, the potential social

\footnotetext{
${ }^{1}$ The zero marginal cost (and the zero equilibrium price) assumption is for notational simplification, which has no material impact on the following analysis.

2 Bagnoli and Watts (2003) also assume an extra benefit of this form for consumers who consume a unit of CSR-linked goods, without any exploration on the implications of vertical and horizontal product differentiation.
} 
benefit (ay ) reflects the vertical product differentiation property of a CSR activity because all consumers would potentially benefit from this CSR activity. On the other hand, consumer's perception difficulty $(b \theta)$ captures its horizontal product differentiation property because different consumers tend to have different preferences on a given CSR activity $(y){ }^{3}$ Thus this formulation intends to capture both vertical and horizontal product differentiation of CSR activity. ${ }^{4}$ This extra benefit formulation captures consumers' different willingness-to-pay for a product with a given CSR activity. For instance, De Pelsmacker et al. (2005) empirically show that the average premium of willingness to pay for fair-trade coffee (relative to no-fair-trade coffee) varies from $36 \%$ for the fair-trade lovers to $3 \%$ for the brand lovers.

Next we shall consider the demand function for the CSR product supplied by the two-echelon supply chain consisting of F and S. Assume that the CSR product is priced at $p$ by F. Consumer $\theta$ 's net surpluses are $u_{0}+a y-b \theta-p$ and $u_{0}-p_{0}$ if he/she buys (and consumes) one unit of F's product with the CSR activity $y$ and non-CSR product from other firms in the final market, respectively, where $u_{0}$ is the utility obtained by consuming one unit of non-CSR product. Then the condition under which consumer $\theta$ buys F's CSR product is $a y-b \theta-p \geq p_{0}=c_{0}=0$. Finally, let $\theta_{0}$ be the critical consumer type satisfying $a y-b \theta-p=0$. All consumers with type $\theta \leq \theta_{0}$ will obtain a positive extra benefit by consuming F's CSR product, leading to F's demanded quantity at $p$ to be $q=(a y-p) / b$.

\subsection{The Supply Chain Model}

Let $y_{F}$ and $y_{S}$ be the CSR performance achieved via F's and S's CSR activities respectively, and $y=y_{F}+y_{S}$ be the channel CSR performance. The final demand function for the CSR product provided by the two-echelon supply chain $q=(a y-p) / b$ can be re-written

\footnotetext{
${ }^{3}$ Clearly, for given $a, y$ and $b$, a consumer with a large enough $\theta$ may receive a negative extra benefit by consuming one unit of this CSR good. In this case, consumer $\theta$ personally perceives a negative effect of the social clause corresponding to the given CSR. But for the same $y$, a consumer with a small enough $\theta$ would envisage a positive effect of this social clause.

${ }^{4}$ McWilliams et al. (2006) also believe that CSR can be used as both vertical and horizontal differentiation devices in the field of strategic management.
} 


$$
p=a\left(y_{F}+y_{S}\right)-b q
$$

197

where $p \geq 0$ and $q \geq 0$ are the price and demand quantity, respectively.

In demand function (1), for given $b$ and $y_{F}+y_{S}$, parameter $a$ (the MSBP) determines not only the highest potential willingness-to-pay of consumers in the market segment served by the supply chain (by setting $q=0$ ), but also the maximum scale of this market segment (by setting $p=0$ ). Thus the MSBP parameter $a$ reflects the potential to attract consumers to the CSR product provided by the supply chain.

Parameter $b$ (the MPD) determines the slope of the demand curve for the CSR product market segment and depicts the price sensitivity to demand quantity. Then for given $y_{F}+y_{S}$, $a$ and $p$, parameter $b$ determines how many consumers will purchase the CSR product provided by the supply chain. Note further that $b$ gauges the difficulty for a consumer to personally perceive the benefit of a given CSR activity. A lower $b$ indicates that consumers are easier to perceive the benefit of CSR and tend to get higher extra benefit. Thus the MPD parameter $b$ reveals the attractiveness of the CSR product to consumers.

To summarize, a higher MSBP $(a)$ or a lower MPD $(b)$ indicates that the CSR product is more attractive to consumers, reflecting a higher degree of product differentiation for the CSR product by the supply chain from other firms' non-CSR product in the final market. In this case, the competition tends to be less intensive in the final market for the CSR product by the supply chain and the non-CSR product by its competitors. Based on the product differentiation property, the MSBP parameter $a$ and the MPD parameter $b$ can be used to represent the competition intensity that the supply chain has to face in the final market.

Let $c_{F}>0$ and $c_{S}>0$ be the unit CSR cost incurred by $S$ and $F$, and $\bar{C}_{F} \geq 0$ and $\bar{C}_{S} \geq 0$ be the investment budget set aside for CSR activities by $\mathrm{F}$ and $\mathrm{S}$, respectively. Then $y_{F} \in\left[0, \bar{C}_{F} / c_{F}\right]$ and $y_{S} \in\left[0, \bar{C}_{S} / c_{S}\right]$ specify the CSR performance bounds for $\mathrm{F}$ and $\mathrm{S}$. The unit CSR cost $c_{F}$ and $c_{S}$ can be respectively viewed as parameters to measure F's and S's 
CSR conduct efficiency at an operational level: a higher unit cost indicates a lower of operational efficiency. We call $c_{F}$ and $c_{S}$ respectively the operational efficiency of F's and S's CSR conduct. The CSR investment budget $\bar{C}_{F}$ and $\bar{C}_{S}$ can be seen as parameters to represent the levels of the importance that F and S attach to CSR conduct at a strategic level: a higher budget implies that a supply chain member takes CSR conduct as more important and then allocates more resources to its CSR activity. $\bar{C}_{F}$ and $\bar{C}_{S}$ can then measure the strategic importance of CSR to F and S, respectively. To concentrate on CSR interaction in supply chain operations, other costs such as the CSR- independent portion of production, stocking, and delivery costs are normalized to be zero.

The sequence of decisions is as follows: $\mathrm{F}$ and $\mathrm{S}$ choose $y_{F} \geq 0$ and $y_{S} \geq 0$ simultaneously (This simultaneous-move assumption is relaxed to be sequential-move in Section 3), followed by a wholesale price $w \in\left[0, a\left(y_{F}+y_{S}\right)\right]$ offered by $\mathrm{S}$ (as noted by Cachon (2003), wholesale price contracts are commonly observed in practice). Finally, F makes its purchase decision $q$.

The aforesaid CSR conduct model setting, at the first glance, appears similar to existing literature on quality improvement incentive within a supply chain (see Chao et al. (2009) for an extensive review). However, our model is significantly different from this body of literature in two aspects. Firstly, our research assumes a CSR-dependent demand function while the latter assumes a profitability difference resulted from different quality levels without explicitly considering the impact of quality improvements on demand. Secondly, our model focuses on strategic interactions of CSR conduct in a supply chain under wholesale price contracts, while the latter mainly concentrates on designing quality-related cost sharing contracts between supply chain members for quality improvement.

Moreover, our assumption of a CSR-dependent demand function can be found in recent parallel research on supply chain service competition/coordination. Along this line, Tsay and Agrawal (2000) assume a service-dependent demand function with a substitutive demand effect between two downstream retailers' service levels and examine the impact of relative intensity of price- and service-competition on supply chain operations dynamics. Bernstein and 
Federgruen (2007) use a demand function with the same property as that in Tsay and Agrawal (2000) to investigate the coordination problem in a supply chain consisting of one common supplier and $\mathrm{N}$ retailers. Rather than focusing on downstream competition in the final market, our model is devoted to exploring behavioural interactions of CSR conduct within a supply chain under the assumption that S's and F's CSR activities enable the product supplied by the supply chain to be differentiated both vertically and horizontally from other firms' non-CSR products in the final market. To investigate supply chain coordination where two supply chains, each consisting of one wholesaler and one retailer, compete by service levels, Boyaci and Gallego (2004) adopt the fill rate to measure service levels of the supply chain members, and assume that final demand of each supply chain is determined only by a relative downstream service level, but is independent of upstream service level and retail price (This price-independence assumption is also adopted by Taylor (2002) to describe the impact of sales effort on final market demand). In our model, we assume that the final market demand quantity and retail price are positively associated with both the upstream and the downstream CSR activities. To summarize, the service competition literature is to understand the role of service in downstream competition in the final market, while our model is to explore the upstream-downstream behavioural interactions of CSR conduct in a supply chain. In addition, to describe the impact of service on final demand function, this body of literature follows the theory of industrial organization and views service as a vertical product differentiation device (Tirole, 1988). ${ }^{5}$ With our analysis of the impact of CSR commitment on consumers' extra benefits, this research intends to characterize both vertical and horizontal differentiation properties of CSR conduct.

Finally, a number of authors view CSR conduct as a provision of public goods. Bagnoli and Watts (2003), Kotchen (2006), and Besley and Ghatak (2007) are concerned with inter-firm competition where firms strategically provide certain amount of public goods (CSR performance). And then they analyze the efficiency implication of the public goods provision according to the corresponding market equilibriums. Rather than examining market efficiency under inter-firm competition, we focus on behavioural and operational implications of the strategic cooperation/conflict of CSR conduct within a supply chain under a linear demand

\footnotetext{
${ }^{5}$ Quality is also treated as a vertical differentiation device in the theory of industrial organization.
} 
function (1), in which the parameters $a$ and $b$ reflect competition intensity in the final market.

\subsection{The Equilibriums}

The subgame perfect Nash equilibrium of this three-stage dynamic game can be solved by backward induction.

\section{In stage 3, F selects $q$ to maximize}

$$
\Pi_{F}\left(y_{F}, y_{S}, w, q\right)=\left(a\left(y_{F}+y_{S}\right)-b q\right) q-w q-c_{F} y_{F}
$$

Clearly, $\Pi_{F}$ is concave in $q$. Then the first-order condition implies

$$
q\left(y_{F}, y_{S}, w\right)=\frac{a\left(y_{F}+y_{S}\right)-w}{2 b}
$$

In stage 2, in anticipation of F's reaction captured by (2), S chooses $w$ to maximize ${ }^{6}$

$$
\Pi_{S}\left(y_{F}, y_{S}, w, q\left(y_{F}, y_{S}, w\right)\right)=w q\left(y_{F}, y_{S}, w\right)-c_{S} y_{S}=\frac{a\left(y_{F}+y_{S}\right) w-w^{2}}{2 b}-c_{S} y_{S}
$$

It is easy to check that $\Pi_{s}$ is concave in $w$. From the first-order condition, we have

$$
w^{*}\left(y_{F}, y_{S}\right)=\frac{a\left(y_{F}+y_{S}\right)}{2}
$$

Substituting (3) into (2), one can get

$$
q^{*}\left(y_{F}, y_{S}\right)=\frac{a\left(y_{F}+y_{S}\right)}{4 b}
$$

With the demand function (1), the final market price is

$$
p^{*}\left(y_{F}, y_{S}\right)=\frac{3 a\left(y_{F}+y_{S}\right)}{4}
$$

Further, substituting (3) and (4) into the profit function for S and F, their stage-1 profits are $^{7}$

\footnotetext{
${ }^{6}$ Here, an alternative assumption is that $\mathrm{F}$ and S simultaneously choose $q$ and $w$ in the same stage. In this case, S's profit function is written as $\Pi_{S}\left(y_{F}, y_{S}, w, q\right)=w q-c_{S} y_{S}$ and F's profit function and reaction function are the same as those in the sequential-move case. Next, we will show that the unique Nash equilibrium is $q=0$ and $w=a\left(y_{F}+y_{S}\right)$. Firstly, for any given $q>0$, as S's profit linearly increases in $w$, S's optimal reaction is the upper bound $w=a\left(y_{F}+y_{S}\right)$, which in turn makes $\mathrm{F}$ choose $q=0$ by (2). This implies that any $q>0$ cannot be in a Nash equilibrium. In addition, for $q=0$, if $S$ chooses $w<a\left(y_{F}+y_{S}\right)$, then F will choose $q>0$ as per (2). This confirms that $q=0$ and $w<a\left(y_{F}+y_{S}\right)$ cannot be in an equilibrium, either. Finally, for $w=a\left(y_{F}+y_{S}\right)$, F's optimal reaction is $q=0$, which makes $S$ indifferent for all $w$ in $\left[0, a\left(y_{F}+y_{S}\right)\right]$. Therefore, $\left(q=0, w=a\left(y_{F}+y_{S}\right)\right)$ arises as the unique Nash equilibrium.

${ }^{7}$ In reality, the benefit and the cost of CSR activities do not occur simultaneously. In this case, a discount factor can be added to discount the stage-3 profit. However, it can be easily checked that this modification does not change the main results.
} 


$$
\Pi_{S}^{*}\left(y_{F}, y_{S}\right)=\frac{a^{2}\left(y_{F}+y_{S}\right)^{2}}{8 b}-c_{S} y_{S}
$$

$$
\Pi_{F}^{*}\left(y_{F}, y_{S}\right)=\frac{a^{2}\left(y_{F}+y_{S}\right)^{2}}{16 b}-c_{F} y_{F}
$$

Note that these two profit functions are convex and quadratic, so the profit achieves its maximum at either the upper or lower bound. As such, the optimal reaction of $F(S)$ to its opponent is to choose 0 or $\bar{C}_{F} / C_{F}\left(0\right.$ or $\left.\bar{C}_{S} / C_{S}\right)$, depending on the corresponding axis of symmetry that is contingent upon its opponent's choice $y_{S}\left(y_{F}\right)$. $y_{S}=\bar{C}_{S} / c_{S} \quad$ if $\quad 4 b c_{S} / a^{2}-y_{F} \leq \bar{C}_{S} /\left(2 c_{S}\right)$, implying that $\Pi_{S}^{*}\left(y_{F}, \bar{C}_{S} / c_{S}\right) \geq \Pi_{S}^{*}\left(y_{F}, 0\right)$

Otherwise $y_{S}=0$. To summarize, S's reaction function is

$$
y_{S}=f\left(y_{F}\right) \equiv\left\{\begin{array}{l}
\frac{\bar{C}_{S}}{c_{S}}, \quad \text { if } y_{F} \geq \frac{4 b c_{S}}{a^{2}}-\frac{\bar{C}_{S}}{2 c_{S}} \\
0, \quad \text { otherwise }
\end{array}\right.
$$

In (6), we assume for tie-breaking that $\mathrm{S}$ chooses the greater $y_{S}>0$ when $\Pi_{S}^{*}\left(y_{F}, y_{S}\right)=\Pi_{S}^{*}\left(y_{F}, 0\right)$.

Analogically, F's reaction function is

$$
y_{F}=g\left(y_{S}\right) \equiv\left\{\begin{array}{l}
\frac{\bar{C}_{F}}{c_{F}}, \quad \text { if } y_{S} \geq \frac{8 b c_{F}}{a^{2}}-\frac{\bar{C}_{F}}{2 c_{F}} \\
0, \quad \text { otherwise }
\end{array}\right.
$$

Reaction functions (6) and (7) imply that the greater $y_{S} \quad\left(y_{F}\right)$ chosen by S (F), the more likely its opponent will be induced to select its upper bound $y_{F}=\bar{C}_{F} / c_{F}\left(y_{S}=\bar{C}_{S} / c_{S}\right)$. This reveals the existence of a mutual incentive between $\mathrm{S}$ and $\mathrm{F}$.

The reasons for the existence of this mutual incentive are as follows. Note that (3) and (5) imply that F's profit margin, $a\left(y_{F}+y_{S}\right) / 4$, increases in $y_{S}$. Furthermore, the quantity sold in the final market also increases in $y_{S}$. Thus for a given unit CSR cost $c_{F}$, a higher $y_{S}$ means a higher profit margin for each unit of $y_{F}$. This is likely to stimulate F to choose a higher $y_{F}$. 
On the other hand, since both the wholesale price and order quantity increase in $y_{F}$, $\mathrm{S}$ will reap a higher profit for each unit of $y_{S}$ when $\mathrm{F}$ chooses a higher $y_{F}$. Thus a higher $y_{F}$ tends to induce $\mathrm{S}$ to select a higher $y_{S}$ as well.

Denote

$$
y_{F}^{\#}\left(a, b, \bar{C}_{S}, c_{S}\right) \equiv \frac{4 b c_{S}}{a^{2}}-\frac{\bar{C}_{S}}{2 c_{S}} \text { and } y_{S}^{\#}\left(a, b, \bar{C}_{F}, c_{F}\right) \equiv \frac{8 b c_{F}}{a^{2}}-\frac{\bar{C}_{F}}{2 c_{F}}
$$

It is clear that $y_{F}^{\#}$ decreases in $a$ and $\bar{C}_{S}$ but increases in $b$ and $c_{S}$, and that $y_{S}^{\#}$ decreases in $a$ and $\bar{C}_{F}$ but increases in $b$ and $c_{F}$.

With the reaction functions (6) and (7), the Nash equilibriums of the stage-1 subgame are derived as shown in Lemma 1.

Lemma 1: (i) if $y_{F}^{\#}\left(a, b, \bar{C}_{S}, c_{S}\right) \leq 0$ and $y_{S}^{\#}\left(a, b, \bar{C}_{F}, c_{F}\right) \leq \bar{C}_{S} / c_{S}$, or $y_{S}^{\#}\left(a, b, \bar{C}_{F}, c_{F}\right) \leq 0$ and $y_{F}^{\#}\left(a, b, \bar{C}_{S}, c_{S}\right) \leq \bar{C}_{F} / c_{F}$, then $\left(y_{F}^{*}, y_{S}^{*}\right)=\left(\bar{C}_{F} / c_{F}, \bar{C}_{S} / c_{S}\right)$ is the unique Nash equilibrium.

(ii) if $y_{F}^{\#}\left(a, b, \bar{C}_{S}, c_{S}\right) \leq 0$ and $y_{S}^{\#}\left(a, b, \bar{C}_{F}, c_{F}\right)>\bar{C}_{S} / c_{S}$, then $\left(y_{F}^{*}, y_{S}^{*}\right)=\left(0, \bar{C}_{S} / c_{S}\right)$ is the unique Nash equilibrium.

(iii) if $y_{S}^{\#}\left(a, b, \bar{C}_{F}, c_{F}\right) \leq 0$ and $y_{F}^{\#}\left(a, b, \bar{C}_{S}, c_{S}\right)>\bar{C}_{F} / c_{F}$, then $\left(y_{F}^{*}, y_{S}^{*}\right)=\left(\bar{C}_{F} / c_{F}, 0\right)$ is the unique Nash equilibrium.

(iv) if $0<y_{F}^{\#}\left(a, b, \bar{C}_{S}, c_{S}\right) \leq \bar{C}_{F} / c_{F}$ and $0<y_{S}^{\#}\left(a, b, \bar{C}_{F}, c_{F}\right) \leq \bar{C}_{S} / c_{S}$, then $\left(y_{F}^{*}, y_{S}^{*}\right)=$ $(0,0)$ and $\left(y_{F}^{*}, y_{S}^{*}\right)=\left(\bar{C}_{F} / c_{F}, \bar{C}_{S} / c_{S}\right)$ are the two Nash equilibriums.

(v) if $y_{F}^{\#}\left(a, b, \bar{C}_{S}, c_{S}\right)>0 \quad$ and $y_{S}^{\#}\left(a, b, \bar{C}_{F}, c_{F}\right)>\bar{C}_{S} / c_{S}$, or $\quad y_{S}^{\#}\left(a, b, \bar{C}_{F}, c_{F}\right)>0 \quad$ and $y_{F}^{\#}\left(a, b, \bar{C}_{S}, c_{S}\right)>\bar{C}_{F} / c_{F}$, then $\left(y_{F}^{*}, y_{S}^{*}\right)=(0,0)$ is the unique Nash equilibrium.

The proof of this lemma is given in the Appendix A.1.

With the aforesaid equilibrium result for the stage- 1 subgame, the subgame perfect Nash equilibriums of the three-stage game are derived as follows. The proof can be completed by plugging $\left(y_{F}^{*}, y_{S}^{*}\right)$ in Lemma 1 into (3) and (4) as well as the profit functions for S and F.

Proposition 1: (i) if $y_{F}^{\#}\left(a, b, \bar{C}_{S}, c_{S}\right) \leq 0$ and $y_{S}^{\#}\left(a, b, \bar{C}_{F}, c_{F}\right) \leq \bar{C}_{S} / c_{S}$, or $y_{S}^{\#}\left(a, b, \bar{C}_{F}, c_{F}\right) \leq 0$ 
and $y_{F}^{\#}\left(a, b, \bar{C}_{S}, c_{S}\right) \leq \bar{C}_{F} / c_{F}$, the equilibrium path of the three-stage game model is

$$
\text { (E) }\left\{\left(y_{S}^{*}, y_{F}^{*}\right)=\left(\frac{\bar{C}_{S}}{c_{S}}, \frac{\bar{C}_{F}}{c_{F}}\right) \rightarrow w^{*}=\frac{a}{2}\left(\frac{\bar{C}_{F}}{c_{F}}+\frac{\bar{C}_{S}}{c_{S}}\right) \rightarrow q^{*}=\frac{a}{4 b}\left(\frac{\bar{C}_{F}}{c_{F}}+\frac{\bar{C}_{S}}{c_{S}}\right)\right\}
$$

and the corresponding equilibrium profits are $\Pi_{F}^{*}\left(y_{F}^{*}, y_{S}^{*}\right)=a^{2}\left(\bar{C}_{F} / c_{F}+\bar{C}_{S} / c_{S}\right)^{2} /(16 b)-\bar{C}_{F}$ and $\Pi_{S}^{*}\left(y_{F}^{*}, y_{S}^{*}\right)=a^{2}\left(\bar{C}_{F} / c_{F}+\bar{C}_{S} / c_{S}\right)^{2} /(8 b)-\bar{C}_{S}$.

(ii) if $y_{F}^{\#}\left(a, b, \bar{C}_{S}, c_{S}\right) \leq 0$ and $y_{S}^{\#}\left(a, b, \bar{C}_{F}, c_{F}\right)>\bar{C}_{S} / c_{S}$, the equilibrium path is $\left\{\left(y_{F}^{*}, y_{S}^{*}\right)=\left(0, \bar{C}_{S} / c_{S}\right) \rightarrow w^{*}=a \bar{C}_{S} /\left(2 c_{S}\right) \rightarrow q^{*}=a \bar{C}_{S} /\left(4 b c_{S}\right)\right\} \quad$ and the corresponding equilibrium profits are $\Pi_{F}^{*}\left(y_{F}^{*}, y_{S}^{*}\right)=a^{2}\left(\bar{C}_{S} / c_{S}\right)^{2} /(16 b)$ and $\Pi_{S}^{*}\left(y_{F}^{*}, y_{S}^{*}\right)=a^{2}\left(\bar{C}_{S} / c_{S}\right)^{2} /(8 b)-\bar{C}_{S}$.

(iii) if $y_{S}^{\#}\left(a, b, \bar{C}_{F}, c_{F}\right) \leq 0$ and $y_{F}^{\#}\left(a, b, \bar{C}_{S}, c_{S}\right)>\bar{C}_{F} / c_{F}$, the equilibrium path is $\left\{\left(y_{F}^{*}, y_{S}^{*}\right)=\left(\bar{C}_{F} / c_{F}, 0\right) \rightarrow w^{*}=a \bar{C}_{F} /\left(2 c_{F}\right) \rightarrow q^{*}=a \bar{C}_{F} /\left(4 b c_{F}\right)\right\}$, and the corresponding equilibrium profits are $\Pi_{F}^{*}\left(y_{F}^{*}, y_{S}^{*}\right)=a^{2}\left(\bar{C}_{F} / c_{F}\right)^{2} /(16 b)-\bar{C}_{F}$ and $\Pi_{S}^{*}\left(y_{F}^{*}, y_{S}^{*}\right)=a^{2}\left(\bar{C}_{F} / c_{F}\right)^{2} /(8 b)$.

(iv) if $0<y_{F}^{\#}\left(a, b, \bar{C}_{S}, c_{S}\right) \leq \bar{C}_{F} / c_{F}$ and $0<y_{S}^{\#}\left(a, b, \bar{C}_{F}, c_{F}\right) \leq \bar{C}_{S} / c_{S}$, there exist two equilibrium paths (E) and $\left\{\left(y_{F}^{*}, y_{S}^{*}\right)=(0,0) \rightarrow w^{*}=0 \rightarrow q^{*}=0\right\}$, and the corresponding equilibrium profits are $\Pi_{F}^{*}\left(y_{F}^{*}, y_{S}^{*}\right)=a^{2}\left(\bar{C}_{F} / c_{F}+\bar{C}_{S} / c_{S}\right)^{2} /(16 b)-\bar{C}_{F}$ and $\Pi_{S}^{*}\left(y_{F}^{*}, y_{S}^{*}\right)=$ $a^{2}\left(\bar{C}_{F} / c_{F}+\bar{C}_{S} / c_{S}\right)^{2} /(8 b)-\bar{C}_{S}$, and $\Pi_{F}^{*}\left(y_{F}^{*}, y_{S}^{*}\right)=0$ and $\Pi_{S}^{*}\left(y_{F}^{*}, y_{S}^{*}\right)=0$, respectively.

(v) if $y_{F}^{\#}\left(a, b, \bar{C}_{S}, c_{S}\right)>0$ and $y_{S}^{\#}\left(a, b, \bar{C}_{F}, c_{F}\right)>\bar{C}_{S} / c_{S}$, or $y_{S}^{\#}\left(a, b, \bar{C}_{F}, c_{F}\right)>0$ and $y_{F}^{*}\left(a, b, \bar{C}_{S}, c_{S}\right)>\bar{C}_{F} / c_{F}$, the equilibrium path is $\left\{\left(y_{F}^{*}, y_{S}^{*}\right)=(0,0) \rightarrow w^{*}=0 \rightarrow q^{*}=0\right\}$, and the corresponding equilibrium profits are $\Pi_{F}^{*}\left(y_{F}^{*}, y_{S}^{*}\right)=0$ and $\Pi_{S}^{*}\left(y_{F}^{*}, y_{S}^{*}\right)=0$.

\subsection{Main Results}

Next, comparative statics are presented about the equilibriums derived in Section 2.2. In the following study, it is assumed that changes are examined one at a time. When one parameter is considered for possible changes, all other parameters are assumed to remain constant.

Proposition 2: Denote the system-wide profit by $\Pi^{*}=\Pi_{F}^{*}+\Pi_{S}^{*}$, then

(i) The equilibrium profits $\Pi_{F}^{*}, \Pi_{S}^{*}$ and $\Pi^{*}$ are nondecreasing in $\bar{C}_{S}, \bar{C}_{F}$, and $a$, 
respectively;

(ii) The equilibrium profits $\Pi_{F}^{*}, \Pi_{S}^{*}$ and $\Pi^{*}$ are nonincreasing in $c_{S}, c_{F}$, and $b$, respectively. The proof of Proposition 2 is provided in Appendix A.2.

Remark 1: The exogenous parameters in this model can be categorized into three groups: market competition intensity parameters $a$ and $b$, CSR strategic importance parameters $\bar{C}_{S}$ and $\bar{C}_{F}$, and CSR operational efficiency parameters $c_{S}$ and $c_{F}$. Proposition 2 examines the relationship between equilibrium profit functions (both individual and channel) and these exogenous parameters. For market parameters $a$ (the MSBP) and $b$ (the MPD), $a$ characterizes the level of the vertical product differentiation of CSR performance. Proposition 2 indicates that a higher MSBP (i.e. a higher level of vertical differentiation) leads to higher profitability (both individually and globally). As for $b$, the MPD reflects the horizontal product differentiation role of CSR performance and is interpreted as the difficulty for consumers to perceive the benefit of CSR activities. Proposition 2 demonstrates that a higher MPD (i.e. a higher level of perception difficulty or a lower level of horizontal differentiation) tends to result in lower equilibrium profitability for both individuals and the whole channel. The intuition is clear: for a higher $a$ (a lower $b$ ), CSR commitment makes the supply chain's product easier to be differentiated from non-CSR goods from competitors and more attractive to consumers, thereby lowering competition intensity in the final market and resulting in higher profitability. For strategic importance parameters $\bar{C}_{S}$ and $\bar{C}_{F}$ and the operational efficiency parameters $c_{S}$ and $c_{F}$, due to the symmetry of the game model, it is only necessary to consider $\bar{C}_{S}$ and $c_{S}$ as $\bar{C}_{F}$ and $c_{F}$ can be discussed similarly. Proposition 2 shows that both individual and channel profitability increases with a higher social responsibility budget $\bar{C}_{S}$ and decreases in the unit CSR cost $c_{S}$. Thus proposition 2 furnishes a theoretical basis for supply chain members to highlight the importance with a higher commitment to CSR activities at strategic level (higher $\bar{C}_{S}$ and $\bar{C}_{F}$ ) and improve their efficiency in social responsibility conduct at an operational level (lower $c_{S}$ and $c_{F}$ ). This 
result is consistent with the observation that more and more supply chain members (especially the primary members) have invested more and more resources in addressing social and/or environmental problems and enhanced their efficiency via technological and/or organizational improvements. For example, Cone/Roper Cause Related Trends Report (1999) points out that nearly $50 \%$ of larger corporations have programs associated with social issues.

Proposition 3: For the six market, strategic importance and operational efficiency parameters, $\bar{C}_{S}, \bar{C}_{F}, a, c_{S}, c_{F}$ and $b$,

(i) given $\bar{C}_{F}, a, c_{S}, c_{F}$ and $b$, there exists $\bar{C}_{S}^{\#} \equiv \bar{C}_{S}^{\#}\left(\bar{C}_{F}, a, c_{S}, c_{F}, b\right)$ such that (E) is the unique subgame perfect Nash equilibrium for all $\bar{C}_{S} \geq \bar{C}_{S}^{\#}$;

(ii) given $\bar{C}_{S}, a, c_{S}, c_{F}$ and $b$, there exists $\bar{C}_{F}^{\#} \equiv \bar{C}_{F}^{\#}\left(\bar{C}_{S}, a, c_{S}, c_{F}, b\right)$ such that (E) is the unique subgame perfect Nash equilibrium for all $\bar{C}_{F} \geq \bar{C}_{F}^{\#}$;

(iii)given $\bar{C}_{S}, \bar{C}_{F}, c_{S}, c_{F}$ and $b$, there exists $a^{\#} \equiv a^{\#}\left(\bar{C}_{S}, \bar{C}_{F}, c_{S}, c_{F}, b\right)$ such that $(\mathrm{E})$ is the unique subgame perfect Nash equilibrium for all $a \geq a^{\#}$;

(iv)given $\bar{C}_{S}, \bar{C}_{F}, a, c_{F}$ and $b$, there exists $c_{S}^{\#} \equiv c_{S}^{\#}\left(\bar{C}_{S}, \bar{C}_{F}, a, c_{F}, b\right)$ such that (E) is the unique subgame perfect Nash equilibrium for all $c_{S} \leq c_{S}^{\#}$;

(v) given $\bar{C}_{S}, \bar{C}_{F}, a, c_{S}$ and $b$, there exists $c_{F}^{\#} \equiv c_{F}^{\#}\left(\bar{C}_{S}, \bar{C}_{F}, a, c_{S}, b\right)$ such that (E) is the unique subgame perfect Nash equilibrium for all $c_{F} \leq c_{F}^{\#}$;

(vi)given $\bar{C}_{S}, \bar{C}_{F}, a, c_{S}$ and $c_{F}$, there exists $b^{\#} \equiv b^{\#}\left(\bar{C}_{S}, \bar{C}_{F}, a, c_{S}, c_{F}\right)$ such that (E) is the unique subgame perfect Nash equilibrium for all $b \leq b^{\#}$.

The proof of Proposition 3 appears in Appendix A.3.

Remark 2: Proposition 3 demonstrates that both $\mathrm{S}$ and $\mathrm{F}$, constrained by $y_{S} \in\left[0, \bar{C}_{S} / c_{S}\right]$ and $y_{F} \in\left[0, \bar{C}_{F} / c_{F}\right]$, will choose their maximum CSR performance $y_{S}^{*}=\bar{C}_{S} / c_{S}$ and $y_{F}^{*}=$ $\bar{C}_{F} / C_{F}$ as their unique equilibrium as long as any of the six exogenous parameters $\bar{C}_{S}, \bar{C}_{F}$, $a, c_{S}, \quad c_{F}$, and $b$ is extended beyond certain critical threshold $\left(\bar{C}_{S} \geq \bar{C}_{S}^{\#}, \bar{C}_{F} \geq \bar{C}_{F}^{\#}\right.$, 
$a \geq a^{\#}, c_{S} \leq c_{S}^{\#}, \quad c_{F} \leq c_{F}^{\#}$, or $\left.b \leq b^{\#}\right)$. Each threshold therein is determined one at a time by keeping the other five parameters constant. Note that Proposition 2 reveals that the profit functions for S, F, and the whole channel increase in $\bar{C}_{S}, \bar{C}_{F}$ and $a$, and decrease in $c_{S}, c_{F}$ and $b$. Therefore, as long as $\bar{C}_{S}, \bar{C}_{F}$, or $a$ is increased above its lower bound, $\bar{C}_{S}^{\#}$, $\bar{C}_{F}^{\#}$, or $a^{\#}$, or $c_{S}, c_{F}$, or $b$ is decreased below its upper bound $c_{S}^{\#}, c_{F}^{\#}$, or $b^{\#}$, a win-win scenario arises in the sense that the supply chain system not only achieves its maximum CSR performance $y_{S}^{*}=\bar{C}_{S} / c_{S}$ and $y_{F}^{*}=\bar{C}_{F} / c_{F}$, but also enhances its profitability for both individual members and the whole channel. This research finding supports existing empirical studies reported in Margolis and Walsh (2001) and Orlitzky et al. (2003): CSR performance is positively related to corporate financial performance. Finally, Proposition 3 explores potential venues for supply chain practitioners to reconcile CSR performance with the profitability of supply chain operations: choosing CSR initiatives with a higher MSBP and/or a lower MPD, raising resource commitment to CSR activities, and improving CSR operational efficiency.

Note that the two-echelon supply chain considered here is characterized by strategic importance parameters $\left(\bar{C}_{S}\right.$ and $\left.\bar{C}_{F}\right)$ and operational efficiency parameters $\left(c_{S}\right.$, and $\left.c_{F}\right)$. We shall examine more carefully how the corresponding system parameter thresholds obtained in Proposition $3, \bar{C}_{S}^{\#}, \bar{C}_{F}^{\#}, c_{S}^{\#}$, and $c_{F}^{\#}$, are affected by the changes in other exogenous parameters. Define $\bar{C}_{S}^{\#}\left(\bar{C}_{F}, c_{S}, c_{F}, a, b\right)$ as

$$
\begin{aligned}
\bar{C}_{S}^{\#}\left(\bar{C}_{F}, c_{S}, c_{F}, a, b\right) \equiv & \min \left\{\bar{C}_{S} \geq 0: F_{1}\left(\bar{C}_{S}\right) \leq 0 \text { or } F_{2}\left(\bar{C}_{S}\right) \leq 0\right\} \\
& =\left\{\begin{array}{l}
0, \text { if } \frac{8 b c_{F}}{a^{2}}-\frac{\bar{C}_{F}}{2 c_{F}} \leq 0 \text { and } \frac{4 b c_{S}}{a^{2}}-\frac{\bar{C}_{F}}{c_{F}} \leq 0 \\
\min \left\{\bar{C}_{S_{1}}^{\#}, \bar{C}_{S_{2}}^{\#}\right\}, \text { if } \frac{8 b c_{F}}{a^{2}}-\frac{\bar{C}_{F}}{2 c_{F}} \leq 0 \text { and } \frac{4 b c_{S}}{a^{2}}-\frac{\bar{C}_{F}}{c_{F}}>0 \\
\bar{C}_{S_{1}}^{\#}, \text { otherwise }
\end{array}\right.
\end{aligned}
$$

and similarly define as $\bar{C}_{F}^{\#}\left(\bar{C}_{S}, c_{S}, c_{F}, a, b\right), c_{S}^{\#}\left(\bar{C}_{S}, \bar{C}_{F}, c_{F}, a, b\right)$ and $c_{F}^{\#}\left(\bar{C}_{S}, \bar{C}_{F}, c_{s}, a, b\right)$ as

$$
\bar{C}_{F}^{\#}\left(\bar{C}_{S}, c_{S}, c_{F}, a, b\right)=\min \left\{\bar{C}_{F} \geq 0: F_{1}\left(\bar{C}_{F}\right) \leq 0 \text { or } F_{2}\left(\bar{C}_{F}\right) \leq 0\right\}
$$




$$
c_{S}^{\#}\left(\bar{C}_{S}, \bar{C}_{F}, c_{F}, a, b\right)=\max \left\{c_{S}>0: F_{1}\left(c_{S}\right) \leq 0 \text { or } F_{2}\left(c_{S}\right) \leq 0\right\}
$$

$$
c_{F}^{\#}\left(\bar{C}_{S}, \bar{C}_{F}, c_{s}, a, b\right)=\max \left\{c_{F}>0: F_{1}\left(c_{F}\right) \leq 0 \text { or } F_{2}\left(c_{F}\right) \leq 0\right\}
$$

439

440

Proposition 4: For the four system parameter thresholds given in (8)-(11),

(i) let $a$ be the only variable, if $a_{1} \geq a_{2}$, then $\bar{C}_{S}^{\#}\left(a_{1}\right) \leq \bar{C}_{S}^{\#}\left(a_{2}\right), \quad \bar{C}_{F}^{\#}\left(a_{1}\right) \leq \bar{C}_{F}^{\#}\left(a_{2}\right)$, $c_{S}^{\#}\left(a_{1}\right) \geq c_{S}^{\#}\left(a_{2}\right)$ and $c_{F}^{\#}\left(a_{1}\right) \geq c_{F}^{\#}\left(a_{2}\right)$;

(ii) let $b$ be the only variable, if $b_{1} \geq b_{2}$, then $\bar{C}_{S}^{\#}\left(b_{1}\right) \geq \bar{C}_{S}^{\#}\left(b_{2}\right), \quad \bar{C}_{F}^{\#}\left(b_{1}\right) \geq \bar{C}_{F}^{\#}\left(b_{2}\right)$, $c_{S}^{\#}\left(b_{1}\right) \leq c_{S}^{\#}\left(b_{2}\right)$ and $c_{F}^{\#}\left(b_{1}\right) \leq c_{F}^{\#}\left(b_{2}\right) ;$

(iii) let $\bar{C}_{F}$ be the only variable, if $\bar{C}_{F}^{1} \geq \bar{C}_{F}^{2}$, then $\bar{C}_{S}^{\#}\left(\bar{C}_{F}^{1}\right) \leq \bar{C}_{S}^{\#}\left(\bar{C}_{F}^{2}\right), \quad c_{S}^{\#}\left(\bar{C}_{F}^{1}\right) \geq c_{S}^{\#}\left(\bar{C}_{F}^{2}\right)$ and $C_{F}^{\#}\left(\bar{C}_{F}^{1}\right) \geq c_{F}^{\#}\left(\bar{C}_{F}^{2}\right)$

(iv) let $c_{F}$ be the only variable, if $c_{F}^{1}>c_{F}^{2}$, then $\bar{C}_{S}^{\#}\left(c_{F}^{1}\right) \geq \bar{C}_{S}^{\#}\left(c_{F}^{2}\right), \bar{C}_{F}^{\#}\left(c_{F}^{1}\right) \geq \bar{C}_{F}^{\#}\left(c_{F}^{2}\right)$ and $c_{S}^{\#}\left(c_{F}^{1}\right) \leq c_{S}^{\#}\left(c_{F}^{2}\right) ;$

(v) let $\bar{C}_{S}$ be the only variable, if $\bar{C}_{S}^{1} \geq \bar{C}_{S}^{2}$, then $\bar{C}_{F}^{\#}\left(\bar{C}_{S}^{1}\right) \leq \bar{C}_{F}^{\#}\left(\bar{C}_{S}^{2}\right), \quad C_{F}^{\#}\left(\bar{C}_{S}^{1}\right) \geq c_{F}^{\#}\left(\bar{C}_{S}^{2}\right)$ and $c_{S}^{\#}\left(\bar{C}_{S}^{1}\right) \geq c_{S}^{\#}\left(\bar{C}_{S}^{2}\right)$

(vi) let $c_{S}$ be the only variable, if $c_{S}^{1} \geq c_{S}^{2}$, then $\bar{C}_{S}^{\#}\left(c_{S}^{1}\right) \geq \bar{C}_{S}^{\#}\left(c_{S}^{2}\right), \bar{C}_{F}^{\#}\left(c_{S}^{1}\right) \geq \bar{C}_{F}^{\#}\left(c_{S}^{2}\right)$ and $c_{F}^{\#}\left(c_{S}^{1}\right) \leq c_{F}^{\#}\left(c_{S}^{2}\right)$.

The proof of Proposition 4 is given in Appendix A.4.

Remark 3: Proposition 4 explores how the critical thresholds of the four system parameters are affected by other parameters, thereby revealing the external market characteristics and the internal coordination opportunities for a supply chain to achieve win-win performance. Part (i) indicates that the higher the MSBP (a larger $a$, indicating a higher degree of vertical differentiation and pointing to a higher potential willingness-to-pay), the lower the requirement on the critical thresholds for CSR resource budgets (smaller $\bar{C}_{S}^{\#}$ and $\bar{C}_{F}^{\#}$ ) and operational efficiency (larger $c_{S}^{\#}$ and $c_{F}^{\#}$ ) by S and F, thereby making the supply chain easier to attain the win-win performance scenario (equilibrium E) given in Proposition 3. Conversely, part (ii) 
shows that supply chain members are easier to achieve the win-win performance with lower critical thresholds for CSR resource budgets (smaller $\bar{C}_{S}^{\#}$ and $\bar{C}_{F}^{\#}$ ) and operational efficiency (larger $c_{S}^{\#}$ and $c_{F}^{\#}$ ) when the MPD is lower (a smaller $b$, indicating a higher degree of CSR horizontal differentiation and easier for consumers to perceive the potential social benefit). On the other hand, if the vertical and horizontal differentiation feature of the supply chain CSR product cannot effectively reduce the competition intensity with non-CSR product in the final market (i.e., resulting in a smaller $a$ and/or larger $b$ ), Proposition 4 (i) and (ii) demonstrate that higher thresholds of the system parameters (larger $\bar{C}_{S}^{\#}$ and $\bar{C}_{F}^{\#}$, attaching a higher strategic importance level to CSR conduct, or smaller $c_{S}^{\#}$ and $c_{F}^{\#}$, corresponding to higher operational efficiency requirement) are needed to achieve the win-win scenario in Proposition 3, making it less attainable. This finding is compatible with Bagnoli and Watts' (2003) conclusion that social responsibility performance (the provision of public goods) varies inversely with the competitiveness of private-good market. On the other hand, parts (iii)-(vi) examine how changes in one of the four internal systematic parameter affect the thresholds of the other three systematic parameters. For example, (iii) and (v) demonstrate that if S or F commits more resources to socially responsible activities (a higher budget $\bar{C}_{S}$ or $\bar{C}_{F}$ ), the other member's critical resource budget decreases (a lower $\bar{C}_{F}^{\#}$ or $\bar{C}_{S}^{\#}$ ) and the thresholds of operational efficiencies become lower for both $\mathrm{S}$ and $\mathrm{F}$ (larger $c_{S}^{\#}$ and $c_{F}^{\#}$ ). (iv) and (vi) reveal that the critical operational efficiency of a member has to be higher (a smaller $c_{S}^{\#}$ or $c_{F}^{\#}$ ) if the other member's operational efficiency is low (a larger $c_{F}$ or $c_{S}$ ), but a higher operational efficiency (a smaller $c_{F}$ or $c_{S}$ ) helps to reduce the thresholds of resource budgets (lower $\bar{C}_{F}^{\#}$ and $\left.\bar{C}_{S}^{\#}\right)$. (iii)-(vi) shed significant insights into the opportunities of coordinating supply chain CSR resource commitment (the strategic importance) and operational efficiency based on the mutual incentive mechanism for the two supply chain members: if a member wishes to induce the other member to attain the win-win performance, it should increase its CSR resource budget or CSR operational efficiency so that the corresponding thresholds for its partner can be 
reduced, thereby making it easier for its partner to enter into the commitment. Furthermore, Proposition 2 points out that both individual and channel profitability will be improved if CSR resource budgets and operational efficiency are increased. Therefore, this mutual incentive makes the recommendation implementable for both members to raise their standards in CSR resource budgets and operational efficiency whereby enhancing their profitability and attaining the win-win performance scenario.

\section{The Role of Prior Commitment}

In Sections 2, it is assumed that S and F choose their CSR activity levels simultaneously. This simultaneous-move assumption cannot accommodate the situation that one supply chain member announces its commitment to CSR investment prior to the other member's decision and how the other member responds to this prior commitment. This section relaxes the simultaneous-move assumption and considers the case that $\mathrm{S}$ and $\mathrm{F}$ make their choices sequentially. Without loss generality, the following study entertains the case that S first chooses $y_{S}$ and, then, F selects $y_{F}$, while the other assumptions remain as is in Section 2. This consideration results in a four-stage sequential-move game: $\mathrm{S}$ first chooses $y_{S}$, the firm then selects $y_{F}$ in stage 2, followed by S's choice of $w$ in stage 3, and finally F's decision $q$. This model can be imagined as an abstraction of a manufacture-distributor supply chain where the manufacturer (S here) is the primary member and makes the first move.

In this model, for any given $y_{S}$ selected by S, F's reaction is captured by (6) in Section 2 where $y_{F}^{*}=\bar{C}_{F} / c_{F}$ if $y_{S} \geq y_{S}^{\#}=8 b c_{F} / a^{2}-\bar{C}_{F} /\left(2 c_{F}\right)$ or 0 if $y_{S} \leq y_{S}^{\#}$. Substituting (6) into S’s profit function $\Pi_{S}^{*}\left(y_{F}, y_{S}\right)$ yields

$$
\Pi_{S D}^{*}\left(y_{S}\right)=\left\{\begin{array}{l}
\frac{a^{2}\left(\bar{C}_{F} / c_{F}+y_{S}\right)^{2}}{8 b}-c_{S} y_{S}, \quad \text { if } y_{S} \geq y_{S}^{\#} \\
\frac{a^{2} y_{S}^{2}}{8 b}-c_{S} y_{S}, \quad \text { otherwise }
\end{array}\right.
$$

where the subscript " $D$ " is introduced to differentiate the dynamics of this sequential-move game from the simultaneous- move case in Section 2.

Proposition 5: For the four-stage sequential-move game, 
(E1) $\left\{y_{S}^{*}=\frac{\bar{C}_{S}}{c_{S}} \rightarrow y_{F}^{*}=\frac{\bar{C}_{F}}{c_{F}} \rightarrow w^{*}=\frac{a}{2}\left(\frac{\bar{C}_{F}}{c_{F}}+\frac{\bar{C}_{S}}{c_{S}}\right) \rightarrow q^{*}=\frac{a}{4 b}\left(\frac{\bar{C}_{F}}{c_{F}}+\frac{\bar{C}_{S}}{c_{S}}\right)\right\}$

is the unique subgame perfect Nash equilibrium if any of the following three conditions is satisfied:

(i) $y_{F}^{\#}\left(a, b, \bar{C}_{S}, c_{S}\right) \leq 0$ and $y_{S}^{\#}\left(a, b, \bar{C}_{F}, c_{F}\right) \leq \bar{C}_{S} / c_{S}$,

(ii) $y_{S}^{\#}\left(a, b, \bar{C}_{F}, c_{F}\right) \leq 0$ and $y_{F}^{\#}\left(a, b, \bar{C}_{S}, c_{S}\right) \leq \bar{C}_{F} / c_{F}$,

(iii) $0<y_{F}^{\#}\left(a, b, \bar{C}_{S}, c_{S}\right) \leq \bar{C}_{F} / c_{F}$ and $0<y_{S}^{\#}\left(a, b, \bar{C}_{F}, c_{F}\right) \leq \bar{C}_{S} / c_{S}$.

The proof of Proposition 5 is provided in Appendix A.5.

Remark 4: Conditions (i) and (ii) here correspond to Case (i), and condition (iii) is the same as Case (iv) in Lemma 1 and Proposition 1 in Section 2, respectively. In the simultaneous-move game, (E) arises as the unique desired equilibrium only if (i) or (ii) is satisfied. Proposition 5 demonstrates that another avenue (iii), in addition to (i) and (ii), becomes available for $\mathrm{S}$ and $\mathrm{F}$ to reach the unique desired equilibrium (E1) in the sequential-move case. (E) and (E1) are claimed as the desired equilibrium in the sense that both the CSR performance and profitability (individual and system-wide) are maximized in these cases compared to other possible equilibriums. This additional avenue (iii) becomes possible because the first-mover's prior commitment to CSR, $y_{S}^{*}=\bar{C}_{S} / c_{S}$ or $y_{F}^{*}=\bar{C}_{F} / c_{F}$, deters its partner from choosing $y_{F}=0$ or $y_{S}=0$ due to the profit maximization consideration. Therefore, Proposition 5 can be interpreted as that a prior commitment to CSR performance from one supply chain member furnishes another vehicle to achieve the win-win performance scenario, enhances the mutual incentive between the two supply chain members, and makes the win-win performance more likely to be attained. This finding helps us to understand the case of Starbucks: while enjoying a rising tendency of profitability as measured by net earnings and EPS, Starbucks takes its initiative and introduces a C.A.F.E. certification program to encourage socially and environmentally responsible practices by its suppliers (Starbucks 2004-2006; Lee et al. 2007). In short, prior commitment can be viewed as another way (relative to the simultaneous-move case) to enhance the mutual incentive and foster the realization of the win-win performance scenario. 


\section{Discussions}

In this section, the constant marginal CSR cost assumption in Section 2 is relaxed to allow for a quadratic term in the CSR cost function. Assume that the CSR cost function for F and S are $c_{F} y_{F}+d_{F} y_{F}^{2} / 2$ and $c_{S} y_{S}+d_{S} y_{S}^{2} / 2$, respectively, where $d_{F} \geq 0$ and $d_{S} \geq 0 .{ }^{8}$ In this case, the profit functions of $\mathrm{S}$ and $\mathrm{F}$ in the first stage are

$$
\begin{aligned}
& \Pi_{S}^{*}\left(y_{F}, y_{S}\right)=\frac{a^{2}\left(y_{F}+y_{S}\right)^{2}}{8 b}-c_{S} y_{S}-\frac{1}{2} d_{S} y_{S}^{2} \\
& \Pi_{F}^{*}\left(y_{F}, y_{S}\right)=\frac{a^{2}\left(y_{F}+y_{S}\right)^{2}}{16 b}-c_{F} y_{F}-\frac{1}{2} d_{F} y_{F}^{2}
\end{aligned}
$$

Proposition 6: Under the quadratic cost function assumption, if $d_{S}<a^{2} /(4 b)$ and $d_{F}<a^{2} /(8 b)$, then all properties in Lemma 1 and Propositions 1-5 remain valid.

The proof of Proposition 6 is provided in Appendix A.6.

Proposition 6 shows that the results in Section 2 and 3 remain true under a quadratic cost function as long as the coefficients of the quadratic terms are not too big. Note that $d_{k}$ reflects the speed at which $k$ 's marginal cost increases in its CSR performance $y_{k}(k=S, F)$. Thus the main results are not only true in a constant-marginal-cost setting (Section 2 and 3), but also remain valid in certain increasing-marginal-cost settings (as long as marginal costs with regard to CSR activity do not increase too rapidly).

\section{Concluding Remarks}

In this paper we take a strategic CSR view and assume that relative to a non-CSR product, a CSR product provides consumers with some extra benefit which varies across those consumers. This assumption implies that CSR can be used as both a vertical and horizontal product differentiation device. The demand function is deduced for the CSR product provided by a twoechelon supply chain based on the price competition equilibrium in the final market. With this demand function, we investigate how supply chain members interact with respect to their CSR behaviour from a game-theoretic perspective. Subgame perfect Nash equilibriums are derived

\footnotetext{
${ }^{8}$ Röller (1990) theoretically shows that a quadratic cost function can behave well for analyzing global cost concepts (e.g. diminishing marginal returns (or increasing marginal cost)) by properly choosing the parameters. In the OM/OR area, Tsay and Agrawal (2000), Gurnani et al. (2007), Xiao and Yang (2008) employed quadratic functions of some special form in their research.
} 
for both simultaneous-move and sequential-move game settings and the impact of exogenous parameters on this interaction is also examined. Under a set of simple and intuitive assumptions, the following analytical results are obtained.

(1) There exists a mutual incentive between S and F with respect to their CSR behaviour. This mutual incentive leads to a win-win performance scenario (E) in terms of both CSR and profitability performance as long as exogenous parameters are extended beyond certain critical thresholds (Propositions 2 and 3).

(2) A higher consumer's marginal social benefit potential (MSBP) and a lower consumer's marginal perception difficulty (MPD), pointing to a less intense final market competition environment due to vertical and horizontal product differentiation roles of CSR performance, help to lower the critical thresholds of CSR budgets (reflecting its strategic importance) and operational efficiency by S and F to achieving the win-win performance (parts (i) and (ii) of Proposition 4).

(3) An increase in one supply chain member's CSR budget (operational efficiency) tends to lower its own CSR operational efficiency (budget) threshold and the other member's CSR budget and operational efficiency thresholds, thereby making it more easier to attain the win-win performance scenario (parts (iii)-(vi) of Proposition 4).

(4) A prior commitment to CSR activities by any supply chain member strengthens the mutual incentive and makes the win-win performance scenario (E1) more likely to be realized in the sense that this commitment provides additional vehicles for (E1) to arise as the desired equilibrium (Proposition 5).

Business implications of these research findings are discussed in the remarks. This research, to a certain extent, helps us to understand how businesses interact with each other with respect to their CSR conduct. As stated in the basic model settings, information asymmetry is not considered for the CSR budget or operational efficiency. Further research is needed to accommodate this information asymmetry and other extensions (for example, adding supply chain members to introduce competition within a supply chain system) so that a more complete picture can be portrayed about how supply chain members interact and respond to the call for socially responsible practices.

\section{Appendices. Proofs of Lemma 1 and Propositions}


614 twice at $(0,0)$ and $\left(\bar{C}_{F} / C_{F}, \bar{C}_{S} / C_{S}\right)$, resulting in the two Nash equilibriums. (iv) is thus 615 proved.

\section{Appendix A.1. Proof of Lemma 1}

(i) As the game is symmetric, it is only necessary to show that $y_{F}^{\#}\left(a, b, \bar{C}_{S}, c_{S}\right) \leq 0$ and $y_{S}^{\#}\left(a, b, \bar{C}_{F}, c_{F}\right) \leq \bar{C}_{S} / c_{S}$ imply that $\left(y_{F}^{*}, y_{S}^{*}\right)=\left(\bar{C}_{F} / c_{F}, \bar{C}_{S} / c_{S}\right)$ is the unique Nash equilibrium. As $y_{F}^{\#}\left(a, b, \bar{C}_{S}, c_{S}\right) \leq 0 \leq y_{F}$, it follows that $y_{S}=f\left(y_{F}\right)=\bar{C}_{S} / c_{S}$ for all $y_{F} \in\left[0, \bar{C}_{F} / c_{F}\right]$ as per (5). $y_{S}^{\#}\left(a, b, \bar{C}_{F}, c_{F}\right) \leq \bar{C}_{S} / c_{S}$ implies that $\left[y_{S}^{\#}, \bar{C}_{S} / c_{S}\right] \neq \Phi$. Since $y_{S}=\bar{C}_{S} / c_{S}$, from (6), one can get $y_{F}=g\left(y_{S}\right)=g\left(\bar{C}_{S} / c_{S}\right)=\bar{C}_{F} / c_{F}$. Thus $\left(y_{F}^{*}, y_{S}^{*}\right)=\left(\bar{C}_{F} / c_{F}, \bar{C}_{S} / c_{S}\right)$ is a Nash equilibrium. Suppose that there exists another Nash equilibrium. It has to be one of $(0,0)$, $\left(0, \bar{C}_{S} / c_{S}\right)$, and $\left(\bar{C}_{F} / c_{F}, 0\right)$ based on the reaction functions (5) and (6). Consider $(0,0)$ first. F's optimal reaction to S's choice $y_{S}=0$ is either $y_{F}=0$ if $y_{S}^{\#}\left(a, b, \bar{C}_{F}, c_{F}\right)>0$, or $y_{F}=\bar{C}_{F} / c_{F}$ if $y_{S}^{\#}\left(a, b, \bar{C}_{F}, c_{F}\right) \leq 0$. The latter case implies that $(0,0)$ is not a Nash equilibrium. For the former case, S's optimal reaction to $y_{F}=0$ should be $y_{S}=\bar{C}_{S} / c_{S} \neq 0$ based on (5), leading to a contradiction. Similarly, it can be verified that neither $\left(0, \bar{C}_{S} / c_{S}\right)$ nor $\left(\bar{C}_{F} / c_{F}, 0\right)$ is a Nash equilibrium. Hence, $\left(y_{F}^{*}, y_{S}^{*}\right)=\left(\bar{C}_{F} / c_{F}, \bar{C}_{S} / c_{S}\right)$ is the unique Nash equilibrium.

(ii) $y_{S}^{\#}\left(a, b, \bar{C}_{F}, c_{F}\right)>\bar{C}_{S} / c_{S}$ implies that $\left[y_{S}^{\#}, \bar{C}_{S} / c_{S}\right]=\Phi$. That is, for all $y_{S} \in$ $\left[0, \bar{C}_{S} / c_{S}\right]$, F's optimal reaction is $y_{F}=g\left(y_{S}\right)=0 . y_{F}^{\#}\left(a, b, \bar{C}_{S}, c_{S}\right) \leq 0$ implies that $y_{S}=f\left(y_{F}\right)=\bar{C}_{S} / c_{S}$ for all $y_{F} \in\left[0, \bar{C}_{F} / c_{F}\right]$. Then the two reaction curves uniquely intersect at $\left(0, \bar{C}_{S} / c_{S}\right)$. Thus $\left(y_{F}^{*}, y_{S}^{*}\right)=\left(0, \bar{C}_{S} / c_{S}\right)$ is the unique Nash equilibrium. Due to symmetry of the game model, (iii) can be proved in the same way.

(iv) $0<y_{F}^{\#}\left(a, b, \bar{C}_{S}, c_{S}\right) \leq \bar{C}_{F} / c_{F}$ and $0<y_{S}^{\#}\left(a, b, \bar{C}_{F}, c_{F}\right) \leq \bar{C}_{S} / c_{S}$ imply that $\left[0, y_{F}^{\#}\right) \neq$ $\Phi,\left[y_{F}^{\#}, \bar{C}_{F} / c_{F}\right] \neq \Phi,\left[0, y_{S}^{\#}\right) \neq \Phi$ and $\left[y_{S}^{\#}, \bar{C}_{S} / c_{S}\right] \neq \Phi$. Then the reaction curves intersect 
(v) The symmetry of the game model allows us to consider only the case of $y_{F}^{\#}\left(a, b, \bar{C}_{S}, c_{S}\right)>0$ and $y_{S}^{\#}\left(a, b, \bar{C}_{F}, c_{F}\right)>\bar{C}_{S} / c_{S}$, and the other condition can be confirmed in the same manner. $y_{S}^{\#}\left(a, b, \bar{C}_{F}, c_{F}\right)>\bar{C}_{S} / c_{S}$ implies that $\left[y_{S}^{\#}, \bar{C}_{S} / c_{S}\right]=\Phi$. Then F's optimal 619 reaction is $y_{F}=g\left(y_{S}\right)=0$ for all $y_{S} \in\left[0, \bar{C}_{S} / c_{S}\right]$. So, $y_{F}^{\#}\left(a, b, \bar{C}_{S}, c_{S}\right)>0=y_{F}$ implies that $620 y_{S}=f\left(y_{F}\right)=0 .(\mathrm{v})$ is proved.

\section{Appendix A.2. Proof of Proposition 2}

It is shown below that the equilibrium profits $\Pi_{F}^{*}$ and $\Pi_{S}^{*}$ are nondecreasing in $\bar{C}_{S}$, implying that $\Pi^{*}$ is nondecreasing in $\bar{C}_{s}$ as well. Remaining claims can be proved in a 624 similar fashion. Corresponding to the five equilibrium paths in Proposition 1, the equilibrium 625 profit functions are examined exhaustively as follows:

Case 1: $y_{F}^{\#}\left(a, b, \bar{C}_{S}, c_{S}\right) \leq 0 \quad$ and $y_{S}^{\#}\left(a, b, \bar{C}_{F}, c_{F}\right) \leq \bar{C}_{S} / c_{S}$, or $y_{S}^{\#}\left(a, b, \bar{C}_{F}, c_{F}\right) \leq 0 \quad$ and 627 $y_{F}^{\#}\left(a, b, \bar{C}_{S}, c_{S}\right) \leq \bar{C}_{F} / c_{F}$. Due to symmetry of the game, only the first subcase, $628 y_{F}^{\#}\left(a, b, \bar{C}_{S}, c_{S}\right) \leq 0$ and $y_{S}^{\#}\left(a, b, \bar{C}_{F}, c_{F}\right) \leq \bar{C}_{S} / c_{S}$, is examined. Given that $\bar{C}_{S}$ satisfies 629 $y_{F}^{\#}\left(a, b, \bar{C}_{S}, c_{S}\right) \leq 0$ and $y_{S}^{\#}\left(a, b, \bar{C}_{F}, c_{F}\right) \leq \bar{C}_{S} / c_{S}$, and the other parameters $\bar{C}_{F}, a, c_{S}, c_{F}$ 630 and $b$ remain constant, S's profit function $\Pi_{S}^{*}=a^{2}\left(\bar{C}_{F} / c_{F}+\bar{C}_{S} / c_{S}\right)^{2} /(8 b)-\bar{C}_{S} \quad$ (See

631 Proposition 1) is quadratic and convex with respect to $\bar{C}_{S}$, and its axis of symmetry is $632 \bar{C}_{S}=4 b c_{S}^{2} / a^{2}-c_{S} \bar{C}_{F} / c_{F}$. Furthermore, $y_{F}^{\#}\left(a, b, \bar{C}_{S}, c_{S}\right) \leq 0$ implies that $\bar{C}_{S} \geq 8 b c_{S}^{2} / a^{2}$ $633>4 b c_{S}^{2} / a^{2}-c_{S} \bar{C}_{F} / c_{F}$. Then any $\bar{C}_{S}$ satisfying $y_{F}^{\#}\left(a, b, \bar{C}_{S}, c_{S}\right) \leq 0$ is to the right of the 634 symmetry axis of $\Pi_{s}^{*}$. Thus $\Pi_{s}^{*}$ increases in $\bar{C}_{s}$. From F's profit function given in 635 Proposition 1, $\Pi_{F}^{*}=a^{2}\left(\bar{C}_{F} / c_{F}+\bar{C}_{S} / c_{S}\right)^{2} /(16 b)-\bar{C}_{F}$, it immediately follows that $\Pi_{F}^{*}$ increases 636 in $\bar{C}_{S}$. equilibrium profit function is $\Pi_{S}^{*}=a^{2}\left(\bar{C}_{S} / c_{S}\right)^{2} /(8 b)-\bar{C}_{S}$, and its axis of symmetry is $\bar{C}_{S}=$ 
$4 b c_{S}^{2} / a^{2}$. Again, $y_{F}^{\#}\left(a, b, \bar{C}_{S}, c_{S}\right) \leq 0$ implies that $\bar{C}_{S} \geq 8 b c_{S}^{2} / a>4 b c_{S}^{2} / a^{2}$, indicating that $\bar{C}_{S}$ satisfying $y_{F}^{\#}\left(a, b, \bar{C}_{S}, c_{S}\right) \leq 0$ is to the right of the symmetry axis $\bar{C}_{S}=4 b c_{S}^{2} / a^{2}$. Thus $\Pi_{S}^{*}$ increases in $\bar{C}_{S}$. In addition, $\Pi_{F}^{*}=a^{2}\left(\bar{C}_{S} / c_{S}\right)^{2} /(16 b)$ is clearly increasing in $\bar{C}_{S}$.

Case 3: $y_{S}^{\#}\left(a, b, \bar{C}_{F}, c_{F}\right) \leq 0$ and $y_{F}^{\#}\left(a, b, \bar{C}_{S}, c_{S}\right)>\bar{C}_{F} / c_{F}$. Proposition 1 gives $\Pi_{S}^{*}=$ $a^{2}\left(\bar{C}_{F} / c_{F}\right)^{2} /(8 b)$ and $\Pi_{F}^{*}=a^{2}\left(\bar{C}_{F} / c_{F}\right)^{2} /(16 b)-\bar{C}_{F}$, which are independent of $\bar{C}_{S}$. Then they are nondecreasing in $\bar{C}_{S}$.

Case 4: $0<y_{F}^{\#}\left(a, b, \bar{C}_{S}, c_{S}\right) \leq \bar{C}_{F} / c_{F}$ and $0<y_{S}^{\#}\left(a, b, \bar{C}_{F}, c_{F}\right) \leq \bar{C}_{S} / c_{S}$. There exist two subgame perfect Nash equilibriums. For $\left\{\left(y_{F}^{*}, y_{S}^{*}\right)=(0,0) \rightarrow w^{*}=0 \rightarrow q^{*}=0\right\}, \Pi_{S}^{*}=0$ and $\Pi_{F}^{*}=0$ are constant, and hence, nondecresing in $\bar{C}_{S}$. For the other equilibrium (E), the profit functions are the same as those given in Case 1 . We show that $\Pi_{S}^{*}$ increases in $\bar{C}_{S}$ by checking that $\bar{C}_{S}$ satisfying $y_{F}^{\#}\left(a, b, \bar{C}_{S}, c_{S}\right) \leq \bar{C}_{F} / c_{F}$ is to the right of the symmetry axis of $\Pi_{S}^{*} \quad$ Indeed, $\quad y_{F}^{\#}\left(a, b, \bar{C}_{S}, c_{S}\right) \leq \bar{C}_{F} / c_{F} \quad$ implies that $\bar{C}_{S} \geq 2\left(4 b c_{S}^{2} / a^{2}-c_{S} \bar{C}_{F} / c_{F}\right)>4 b c_{S}^{2} / a^{2}-c_{S} \bar{C}_{F} / c_{F}$ if $4 b c_{S} / a^{2}-\bar{C}_{F} / c_{F}>0$, and it naturally holds that $\bar{C}_{S}>0 \geq 4 b c_{S}^{2} / a^{2}-c_{S} \bar{C}_{F} / c_{F}$ whenever $4 b c_{S} / a^{2}-\bar{C}_{F} / c_{F} \leq 0$. The proof of $\Pi_{F}^{*}$ 's increase in $\bar{C}_{S}$ is similar to that in Case 1 .

Case 5: If $y_{F}^{\#}\left(a, b, \bar{C}_{S}, c_{S}\right)>0$ and $y_{S}^{\#}\left(a, b, \bar{C}_{F}, c_{F}\right)>\bar{C}_{S} / c_{S}$, or $y_{S}^{\#}\left(a, b, \bar{C}_{F}, c_{F}\right)>0$ and $y_{F}^{\#}\left(a, b, \bar{C}_{S}, c_{S}\right)>\bar{C}_{F} / c_{F}, \Pi_{S}^{*}=0$ and $\Pi_{F}^{*}=0$, implying their nondecresing in $\bar{C}_{S}$.

The aforesaid five cases indicate the nondecreasing property of the equilibrium profit functions in $\bar{C}_{S}$ when $\bar{C}_{S}$ changes within the ranges specified by the corresponding conditions. As $y_{F}^{\#}\left(a, b, \bar{C}_{S}, c_{S}\right)=4 b c_{S} / a^{2}-\bar{C}_{S} /\left(2 c_{S}\right)$ decreases in $\bar{C}_{S}$, when $\bar{C}_{S}$ increases from 0 to $+\infty$ with other parameters being fixed, a sufficiently small $\bar{C}_{s}$ exists such as $y_{F}^{\#}\left(a, b, \bar{C}_{S}, c_{S}\right)>0$. For such a given $\bar{C}_{S}$, the conditions in Case 2 and the first scenario of Case 1 do not hold. If the conditions in the second scenario of Case 1 are satisfied, the 
equilibrium profit functions are always characterized by $\Pi_{S}^{*}=a^{2}\left(\bar{C}_{F} / C_{F}+\bar{C}_{S} / c_{S}\right)^{2} /(8 b)$ $-\bar{C}_{S}$ and $\Pi_{F}^{*}=a^{2}\left(\bar{C}_{F} / c_{F}+\bar{C}_{S} / c_{S}\right)^{2} /(16 b)-\bar{C}_{F}$, thereby the nondecreasing property of $\Pi_{S}^{*}$ and $\Pi_{F}^{*}$ in $\bar{C}_{S}$ is ascertained. For remaining cases, when $\bar{C}_{S}$ increases from 0 to $+\infty$, the equilibrium may "jump” following one of the four possible paths: Case $5 \rightarrow$ Case $4 \rightarrow$ Case 1 (if the initial $\bar{C}_{S}$ is selected such that $y_{S}^{\#}\left(a, b, \bar{C}_{F}, c_{F}\right)>0$ and $\left.y_{F}^{\#}\left(a, b, \bar{C}_{S}, c_{S}\right)>\bar{C}_{F} / c_{F}\right)$, Case $4 \rightarrow$ Case 1 (if the initial $\bar{C}_{S}$ is chosen such that $y_{S}^{\#}\left(a, b, \bar{C}_{F}, c_{F}\right)>0$ and $\left.0<y_{F}^{\#}\left(a, b, \bar{C}_{S}, c_{S}\right) \leq \bar{C}_{F} / c_{F}\right)$, Case $5 \rightarrow$ Case $2 \rightarrow$ Case 1 (if the initial $\bar{C}_{S}$ satisfies $y_{F}^{\#}\left(a, b, \bar{C}_{S}, c_{S}\right)>0$ and $\left.y_{S}^{\#}\left(a, b, \bar{C}_{F}, c_{F}\right)>\bar{C}_{S} / c_{S}\right)$, and Case $3 \rightarrow$ Case 1 (if the initial $\bar{C}_{S}$ is chosen such that $\left.y_{S}^{\#}\left(a, b, \bar{C}_{F}, c_{F}\right) \leq 0\right)$. Next, we shall prove that the nondecreasing property remains valid at the threshold where the equilibrium jumps from one case to another along any path.

Consider, for example, one equilibrium jump from Case 5 to Case 4 . In this case, the initial $\bar{C}_{S}$ and other parameters $\bar{C}_{F}, c_{F}, a, b$, and $c_{S}$ satisfy $y_{S}^{\#}\left(a, b, \bar{C}_{F}, c_{F}\right)>0$ and $y_{F}^{\#}\left(a, b, \bar{C}_{S}, c_{S}\right)>\bar{C}_{F} / c_{F}$.

As $y_{F}^{\#}$ decreases in $\bar{C}_{S}$, a sufficiently large $\bar{C}_{S}$ will guarantee that $y_{F}^{\#} \leq \bar{C}_{F} / c_{F}$. Let

$$
\bar{C}_{S}^{*}\left(\bar{C}_{F}, c_{S}, c_{F}, a, b\right)=\min \left\{\bar{C}_{S} \geq 0: y_{F}^{\#}\left(a, b, \bar{C}_{S}, c_{S}\right) \leq \bar{C}_{F} / c_{F}\right\}
$$

Then for any $\bar{C}_{S}<\bar{C}_{S}^{*}$, we have $y_{F}^{*}\left(a, b, \bar{C}_{S}, c_{S}\right)>\bar{C}_{F} / c_{F}$. Lemma 1 implies that the equilibrium is $(0,0)$ for all $\bar{C}_{S}<\bar{C}_{S}^{*}$, and the corresponding profits are $\Pi_{S}^{*}=0$ and $\Pi_{F}^{*}=0$. When $\bar{C}_{S}=\bar{C}_{S}^{*}$, Lemma 1 indicates that both $(0,0)$ and $\left(\bar{C}_{F} / c_{F}, \bar{C}_{S}^{*} / c_{S}\right)$ are equilibriums. For the first scenario, equilibrium profits are both zero for $\mathrm{S}$ and F. For the second scenario, plugging $\bar{C}_{s}^{*}$ into the profit functions in Proposition 1 yields

$$
\Pi_{S}^{*}\left(\frac{\bar{C}_{F}}{c_{F}}, \frac{\bar{C}_{S}^{*}}{c_{S}}\right)=\frac{a^{2}}{8 b}\left(\frac{\bar{C}_{F}}{c_{F}}+\frac{\bar{C}_{S}^{*}}{c_{S}}\right)^{2}-\bar{C}_{S}^{*} \geq \Pi_{S}^{*}\left(\frac{\bar{C}_{F}}{c_{F}}, 0\right)=\frac{a^{2}}{8 b}\left(\frac{\bar{C}_{F}}{c_{F}}\right)>0
$$

and 


$$
\Pi_{F}^{*}\left(\frac{\bar{C}_{F}}{c_{F}}, \frac{\bar{C}_{S}^{*}}{c_{S}}\right)=\frac{a^{2}}{16 b}\left(\frac{\bar{C}_{F}}{c_{F}}+\frac{\bar{C}_{S}^{*}}{c_{S}}\right)^{2}-\bar{C}_{F} \geq \Pi_{F}^{*}\left(0, \frac{\bar{C}_{S}^{*}}{c_{S}}\right)=\frac{a^{2}}{16 b}\left(\frac{\bar{C}_{S}^{*}}{c_{S}}\right)^{2}>0
$$

This indicates that the equilibrium profit functions for $\mathrm{S}$ and $\mathrm{F}$ are nondecreasing after the jump at the threshold $\bar{C}_{S}^{*}$. In a similar fashion, one can verify that this nondecreasing property holds true for all of other possible equilibrium jumps. The proof of Proposition 2 is thus completed.

\section{Appendix A.3. Proof of Proposition 3}

Let

693

$$
\begin{aligned}
F_{1}\left(\bar{C}_{S}, \bar{C}_{F}, c_{S}, c_{F}, a, b\right) & \equiv \max \left\{y_{F}^{\#}\left(a, b, \bar{C}_{S}, c_{S}\right), y_{S}^{\#}\left(a, b, \bar{C}_{S}, c_{S}\right)-\frac{\bar{C}_{S}}{c_{S}}\right\} \\
& =\max \left\{\frac{4 b c_{S}}{a^{2}}-\frac{\bar{C}_{S}}{2 c_{S}}, \frac{8 b c_{F}}{a^{2}}-\frac{\bar{C}_{F}}{2 c_{F}}-\frac{\bar{C}_{S}}{c_{S}}\right\} \\
F_{2}\left(\bar{C}_{S}, \bar{C}_{F}, c_{S}, c_{F}, a, b\right) & \equiv \max \left\{y_{F}^{\#}\left(a, b, \bar{C}_{S}, c_{S}\right)-\frac{\bar{C}_{F}}{c_{F}}, y_{S}^{\#}\left(a, b, \bar{C}_{F}, c_{F}\right)\right\} \\
& =\max \left\{\frac{4 b c_{S}}{a^{2}}-\frac{\bar{C}_{S}}{2 c_{S}}-\frac{\bar{C}_{F}}{c_{F}}, \frac{8 b c_{F}}{a^{2}}-\frac{\bar{C}_{F}}{2 c_{F}}\right\}
\end{aligned}
$$

694

Given $\bar{C}_{F}, c_{S}, c_{F}, a$ and $b$, it is trivial to verify that $F_{1}$ decreases in $\bar{C}_{S}$ and $F_{2}$ decreases in $\bar{C}_{S}$ for $4 b c_{S} / a^{2}-\bar{C}_{S} /\left(2 c_{S}\right)-\bar{C}_{F} / c_{F} \geq 8 b c_{F} / a^{2}-\bar{C}_{F} /\left(2 c_{F}\right)$ and achieves its maximum $4 b c_{S} / a^{2}-\bar{C}_{F} / c_{F}$ at $\bar{C}_{S}=0$, otherwise, $F_{2}$ remains constant at $8 b c_{F} / a^{2}-\bar{C}_{F} /\left(2 c_{F}\right)$. Moreover, both $F_{1}$ and $F_{2}$ are continuous in $\bar{C}_{S}$.

For $F_{1}$, since $F_{1}(0)=\max \left\{4 b c_{S}^{2} / a^{2}, 8 b c_{F} / a^{2}-\bar{C}_{F} / c_{F}\right\}>0$ and $F_{1}(+\infty)=-\infty$, the continuity and monotonicity of $F_{1}$ implies that there exists a unique $\bar{C}_{S_{1}}^{\#}$ such that $F_{1} \leq 0$ for any $\bar{C}_{S} \geq \bar{C}_{S_{1}}^{\#}$

For $F_{2}$, If $8 b c_{F} / a^{2}-\bar{C}_{F} /\left(2 c_{F}\right)>0$, then $F_{2}>0$ for any $\bar{C}_{S} \geq 0$; if $8 b c_{F} / a^{2}-\bar{C}_{F} /\left(2 c_{F}\right) \leq 0$ and $4 b c_{S} / a^{2}-\bar{C}_{F} / c_{F} \leq 0$, then $F_{2} \leq 0$ for any $\bar{C}_{S} \geq 0$; if $8 b c_{F} / a^{2}-\bar{C}_{F} /\left(2 c_{F}\right) \leq 0$ and $4 b c_{S} / a^{2}-\bar{C}_{F} / c_{F}>0$, then there exists a unique $\bar{C}_{S_{2}}^{\#} \in[0,+\infty)$ such that $F_{2} \leq 0$ for any $\bar{C}_{S} \geq \bar{C}_{S_{2}}^{\#}$ due to the monotonic decreasing property of $F_{2}$. 


$$
\begin{aligned}
\bar{C}_{S}^{\#}\left(\bar{C}_{F}, c_{S}, c_{F}, a, b\right) \equiv & \min \left\{\bar{C}_{S} \geq 0: F_{1}\left(\bar{C}_{S}\right) \leq 0 \text { or } F_{2}\left(\bar{C}_{S}\right) \leq 0\right\} \\
& =\left\{\begin{array}{l}
0, \text { if } \frac{8 b c_{F}}{a^{2}}-\frac{\bar{C}_{F}}{2 c_{F}} \leq 0 \text { and } \frac{4 b c_{S}}{a^{2}}-\frac{\bar{C}_{F}}{c_{F}} \leq 0 \\
\min \left\{\bar{C}_{S_{1}}^{\#}, \bar{C}_{S_{2}}^{\#}\right\}, \text { if } \frac{8 b c_{F}}{a^{2}}-\frac{\bar{C}_{F}}{2 c_{F}} \leq 0 \text { and } \frac{4 b c_{S}}{a^{2}}-\frac{\bar{C}_{F}}{c_{F}}>0 \\
\bar{C}_{S_{1}}^{\#}, \text { otherwise }
\end{array}\right.
\end{aligned}
$$

Finally, since $y_{F}^{\#}\left(a, b, \bar{C}_{S}, c_{S}\right) \leq 0$ and $y_{S}^{\#}\left(a, b, \bar{C}_{F}, c_{F}\right) \leq \bar{C}_{S} / c_{S}$ are equivalent to $F_{1} \leq 0$ and $y_{S}^{\#}\left(a, b, \bar{C}_{F}, c_{F}\right) \leq 0$ and $y_{F}^{\#}\left(a, b, \bar{C}_{S}, c_{S}\right) \leq \bar{C}_{F} / c_{F}$ are equivalent to $F_{2} \leq 0$, then $\bar{C}_{S} \geq \bar{C}_{S}^{\#}$ implies (E) is the unique equilibrium by Lemma 1. Part (i) of this proposition is thus proved.

Parts (ii) - (vi) can be verified in the similar fashion. Proposition 3 is then proved.

\section{Appendix A.4. Proof of Proposition 4}

The following proof confirms that $a_{1}>a_{2} \Rightarrow \bar{C}_{S}^{\#}\left(a_{1}\right) \leq \bar{C}_{S}^{\#}\left(a_{2}\right)$ and remaining parts can be proved similarly. Given $\bar{C}_{F}, c_{S}, c_{F}$ and $b$, assume that $a_{1}>a_{2}$. As $F_{1}$ and $F_{2}$ decreases in $a, F_{i}\left(\bar{C}_{s}, a_{2}\right) \leq 0$ implies $F_{i}\left(\bar{C}_{s}, a_{1}\right) \leq 0$ for any $\bar{C}_{s}, \quad i=1,2$. Thus

$$
\left\{\bar{C}_{S} \geq 0: F_{1}\left(\bar{C}_{S}, a_{2}\right) \leq 0 \text { or } F_{2}\left(\bar{C}_{S}, a_{2}\right) \leq 0\right\} \subseteq\left\{\bar{C}_{S} \geq 0: F_{1}\left(\bar{C}_{S}, a_{1}\right) \leq 0 \text { or } F_{2}\left(\bar{C}_{S}, a_{1}\right) \leq 0\right\}
$$

By the definition of $\bar{C}_{S}^{\#}$ in (7) and the nonincreasing property of $F_{i}$ in $\bar{C}_{S}$, we have $\bar{C}_{S}^{\#}\left(a_{1}\right) \leq \bar{C}_{S}^{\#}\left(a_{2}\right)$. The proof of this proposition is thus completed.

\section{Appendix A.5. Proof of Proposition 5}

First, we prove that if $y_{F}^{\#}\left(a, b, \bar{C}_{S}, c_{S}\right) \leq 0$ and $y_{S}^{\#}\left(a, b, \bar{C}_{F}, c_{F}\right) \leq \bar{C}_{S} / c_{S}$, (E1) arises as the unique subgame perfect Nash equilibrium for the four-stage sequential-move game. $y_{F}^{\#}\left(a, b, \bar{C}_{S}, c_{S}\right) \leq 0$ implies that $S$ chooses $y_{S}^{*}=\bar{C}_{S} / c_{S}$ in stage 1 regardless of F's choice in stage 2. Given S's decision $y_{S}^{*}=\bar{C}_{S} / c_{S}$ in stage $1, \mathrm{~F}$ will choose $y_{F}^{*}=\bar{C}_{F} / c_{F}$ in stage 2 due to $y_{S}^{\#}\left(a, b, \bar{C}_{F}, c_{F}\right) \leq \bar{C}_{S} / c_{S}$. Thus (E1) is the unique subgame perfect Nash equilibrium. Due to the symmetry of the game, one can show that (E1) is the unique equilibrium if 
$y_{S}^{\#}\left(a, b, \bar{C}_{F}, c_{F}\right) \leq 0$ and $y_{F}^{\#}\left(a, b, \bar{C}_{S}, c_{S}\right) \leq \bar{C}_{F} / c_{F}$ in a similar way.

Next, we shall show that if $0<y_{F}^{\#}\left(a, b, \bar{C}_{S}, c_{S}\right) \leq \bar{C}_{F} / c_{F}$ and $0<y_{S}^{\#}\left(a, b, \bar{C}_{F}, c_{F}\right) \leq \bar{C}_{S} / c_{S}$, (E1) is also the unique subgame perfect Nash equilibrium. These conditions imply that if $\mathrm{S}$ chooses $y_{S}^{*}=0, \mathrm{~F}$ will respond with $y_{F}^{*}=0$, and if $\mathrm{S}$ selects $y_{S}^{*}=\bar{C}_{S} / c_{S}$, F's optimal response is $y_{F}^{*}=\bar{C}_{F} / C_{F}$. S's profit can be correspondingly given as $\Pi_{S D}^{*}(0)=\Pi_{S}^{*}(0,0)=0$ and $\Pi_{S D}^{*}\left(\bar{C}_{S} / c_{S}\right)=\Pi_{S}^{*}\left(\bar{C}_{F} / c_{F}, \bar{C}_{S} / c_{S}\right)=a^{2}\left(\bar{C}_{F} / c_{F}+\bar{C}_{S} / c_{S}\right)^{2} /(8 b)-\bar{C}_{S}>0=\Pi_{S D}^{*}(0)$ (see the proof of Proposition 2). Therefore, S's optimal decision is $y_{S}^{*}=\bar{C}_{S} / c_{S}$ in stage 1 , leading to the unique equilibrium (E1). This completes the proof of Proposition 5.

\section{Appendix A.6. Proof of Proposition 6}

Proof: $d_{S}<a^{2} /(4 b)$ and $d_{F}<a^{2} /(8 b)$ imply that $\Pi_{S}^{*}$ and $\Pi_{F}^{*}$ are strictly convex in $y_{S}$ and $y_{F}$, respectively. Their symmetric axes are

$$
y_{S}=\frac{4 b c_{S}-a^{2} y_{F}}{a^{2}-4 b d_{S}} \text { and } y_{S}=\frac{8 b c_{F}-a^{2} y_{S}}{a^{2}-8 b d_{F}}
$$

Following the same approaches in Section 2, it can be shown that S's and F's reaction functions are

$$
y_{S}=f\left(y_{F}\right) \equiv\left\{\begin{array}{l}
\frac{-c_{S}+\sqrt{c_{S}^{2}+2 d_{S} \bar{C}_{S}}}{d_{S}}, \\
0, \quad \text { otherwise }
\end{array}\right.
$$

$$
y_{F}=g\left(y_{S}\right) \equiv\left\{\begin{array}{l}
\frac{-c_{F}+\sqrt{c_{F}^{2}+2 d_{F} \bar{C}_{F}}}{d_{F}}, \\
0, \quad \text { otherwise }
\end{array}\right.
$$

where $\left(-c_{k}+\sqrt{c_{k}^{2}+2 d_{k} \bar{C}_{k}}\right) / d_{k}$ is the positive solution to $c_{k} y_{k}+d_{k} y_{k}^{2} / 2=\bar{C}_{k}(k=S$, F ), i.e. firm $k$ 's maximum (feasible) CSR performance under its own CSR budget.

Denote

$$
y_{F}^{\#}\left(a, b, \bar{C}_{S}, c_{S}\right) \equiv \frac{4 b c_{S}-\left(a^{2}-4 b d_{S}\right)}{a^{2}} \times \frac{-c_{S}+\sqrt{c_{S}^{2}+2 d_{S} \bar{C}_{S}}}{d_{S}}
$$




$$
y_{S}^{\#}\left(a, b, \bar{C}_{F}, c_{F}\right) \equiv \frac{8 b c_{F}-\left(a^{2}-8 b d_{F}\right)}{a^{2}} \times \frac{-c_{F}+\sqrt{c_{F}^{2}+2 d_{F} \bar{C}_{F}}}{d_{F}}
$$

Finally, following the step-by-step proofs of Lemma 1 and Propositions 1-5, we can verify that Proposition 6 is true if (1) $y_{F}^{\#}\left(a, b, \bar{C}_{S}, c_{S}\right)$ and $y_{S}^{\#}\left(a, b, \bar{C}_{F}, c_{F}\right)$ therein are respectively replaced with (12) and (13), and (2) $\bar{C}_{k} / c_{k}$ is replaced with $\left(-c_{k}+\sqrt{c_{k}^{2}+2 d_{k} \bar{C}_{k}}\right) / d_{k} \quad(k=S, F)$.

\section{References}

Ageron, B., Gunasekaran, A., Spalanzani, A., 2011. Sustainable supply management: An empirical study, International Journal of Production Economics, forthcoming.

Amaeshi, K., Osuji, O. K., Nnodim, P., 2008. Corporate social responsibility in supply chains of global brands: A boundaryless responsibility? Clarifications, exceptions and implications, Journal of Business Ethics, 81 (1), 223-234.

Bagnoli, M., Watts, S. G., 2003. Selling to socially responsible consumers: Competition and the private provision of public goods, Journal of Economics and Management Strategy, 12(3), 419-445.

Baron, D. P., 2001. Private politics, corporate social responsibility, and integrated strategy, Journal of Economics \& Management Strategy, 10(1), 7-45.

Baron, D. P., 2007. Corporate social responsibility and social entrepreneurship, Journal of Economics \& Management Strategy, 16(3), 683-717.

Besley, T., Ghatak, M., 2007. Retailing public goods: The economics of corporate social responsibility, Journal of Public Economics, 91(9), 1945-1663.

Bernstein, F., Federgruen, A., 2007. Coordination mechanisms for supply chains under price and service competition, Manufacturing and Service Operations Management, 9(3), 242-262.

Bowen, H., 1953. Social Responsibility of the Business, Harper \& Row, New York.

Boyaci, T., Gallego, G., 2004. Supply chain coordination in a market with customer service competition, Production and Operations Management, 13(1), 3-22.

Boyd, D. E., Speckman, R. E., Werhane, P., 2004. Corporate social responsibility and global supply chain management: A normative perspective, Working paper (No. 04-05), University 
of Virginia.

Cachon, G. P., 2003. Supply chain coordination with contracts, In A. G. de Kok, S. C. Graves, eds., Handbooks in OR \& MS, Elsevier.

Calveras, A., Ganuza, J.-J., Llobet, G., 2007. Regulation, corporate social responsibility and activism, Journal of Economics \& Management Strategy, 16(3), 719-740.

Carter, C. R., Kale, R., Grimm, C. M., 2000. Environmental purchasing and firm performance: An empirical investigation, Transportation Research E, 36(3), 219-228.

Carter, C. R., Jennings, M. M., 2002. Social responsibility and supply chain relationships, Transportation Research E, 38(1), 37-52.

Chao, G., Iravari, S., Savaskan, R. C., 2009. Quality improvement incentives and product recall cost sharing contracts, Management Science, 55(7), 1122-1138.

Cone/Roper Cause Related Trends Report. 1999. The Evolution of Cause Branding, Cone, Inc., Boston.

Cruz, J. M., 2008. Dynamics of supply chain networks with corporate social responsibility through integrated environmental decision-making, European Journal of Operational Research, 184(3), 1005-1031.

Cruz, J. M., Wakolbinger, T., 2008. Multiperiod effects of corporate social responsibility on supply chain networks, transaction costs, emissions, and risk. International Journal of Production Economics, 116(1): 61-74

De Pelsmacker, P., Driessen, L., Rayp, G. (2005): Do consumers care about ethics? Willingness to pay for fair-trade coffee. Journal of Consumer Affairs, 39(2), 361-383

The Economist. 2005. The good company (survey), 374, 8410 (Jan. 22).

Friedman, M., 1970. The social responsibility of business is to increase its profits. New York Times Magazine, 13 September, 32-33, 122, 124, 126.

Giovanni, C., Giacinta, C., 2007. Corporate social responsibility and managerial entrenchment, Journal of Economics \& Management Strategy, 16(3), 741-771.

González-Benito, J., González-Benito, O., 2005. Environmental proactivity and business performance: An empirical analysis, Omega, 33(1), 1-15.

Gurnani, H., Erkoc, M.and Luo, Y.. Impact of product and timing of investment decisions on 
supply chain co-opetition. European Journal of operational Research, 2007, 180(1), 224-248.

Hsueh, C.-F., Chang, M.-S., 2008. Equilibrium analysis and corporate social responsibility for supply chain integration, European Journal of Operational Research, 190 (1), 116-129.

Kotchen, M., 2006. Green markets and private provision of public goods, Journal of Political Economy, 114(4), 816-834.

Lee, H. L., Duda, S., James, L., Mackwani, Z., Munoz, R., Volk, D., 2007. Building a sustainable supply chain: Starbucks' Coffee and Farm Equity Program, In: H. L. Lee and C.-Y. Lee (Ed.), Building Supply Chain Excellence in Emerging Economies, Springer, New York.

Margolis, J. D., Walsh, J. P., 2001. People and Profits? The Search for a Link between a Company's Social and Financial Performance, Erlbaum, Mahwah.

McWilliams, A., Siegel, D. S., Wright, P. M., 2006. Corporate social responsibility: Strategic implications, Journal of Management Studies, 43(1), 1-18.

Miao, Z., Cai, S., Xu, D., 2011. Exploring the antecedents of logistics social responsibility: A focus on Chinese firms, International Journal of Production Economics, forthcoming.

Mohr, L. A., Webb, D. J., 2005. The effects of corporate social responsibility and price on consumer responses, Journal of Consumer Affairs, 39(1), 121-147.

Ni, D., Li, K.W., Tang, X., 2010. Social responsibility allocation in two-echelon supply chains: Insights from wholesale price contracts, European Journal of Operational Research, 207 (3), 1269-1279.

Orlitzky M., Schmidt, F. L., Rynes, S. L., 2003. Corporate social and financial performance: A meta-analysis, Organization Studies, 24(3), 403-441.

Pedersen, E. R., Andersen, M., 2006. Safeguarding corporate social responsibility (CSR) in global supply chains: How codes of conduct are managed in buyer-supplier relationships, Journal of Public Affairs, 6(3/4), 228-240.

Röller, L.-H. Proper quadratic cost functions with an application to the bell system, Review of Economics and Statistics, 1990, 72(2), 202-210.

Savaskan, R. C., Bhattacharya, S., Van Wassenhove, L. N., 2004. Closed-loop supply chain models with product remanufacturing, Management Science, 50(2), 239-252. 
832 Starbucks., 2004-2006. Annual CSR Report, http://www.starbucks.com/responsibility,

833 Accessed on September 22, 2010.

834 Taylor, T., 2002. Supply chain coordination under channel rebates with sales effort effects, 835 Management Science, 48(8): 992-1007.

836 Tsay, A. A., Agrawal, N., 2000. Channel dynamics under price and service competition, 837 Manufacturing \& Service Operations Management, 2(4), 372-391.

838 Tirole, J. (1988). The Theory of Industrial Organization, The MIT Press, Massachusetts

839 Windsor, D., 2006. Corporate social responsibility: Three key approaches. Journal of $840 \quad$ Management Studies, 43(1), 93-114.

841 World Bank., 2003. Strengthening Implementation of Corporate Social Responsibility in 842 Global Supply Chains, Washington DC.

843 Xiao, T. and Yang, Q. Price and service competition of supply chains with risk-averse retailers $844 \quad$ under demand uncertainty. International Journal of Production Economics, 2008, 114(1), $845 \quad 187-200$.

846 